Summer 8-22-2020

\title{
A Patient-Centered Approach to Fall Prevention
}

\author{
Elmer Esguerra \\ University of St. Augustine for Health Sciences, e.esguerra@usa.edu
}

DOI: https://doi.org/10.46409/sr.THBW2378

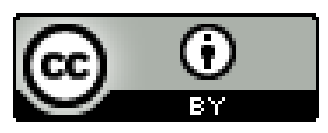

This work is licensed under a Creative Commons Attribution 4.0 License.

Follow this and additional works at: https://soar.usa.edu/scholprojects

Part of the Other Nursing Commons

\section{Recommended Citation}

Esguerra, E. (2020). A Patient-Centered Approach to Fall Prevention. [Doctoral project, University of St Augustine for Health Sciences]. SOAR @ USA: Student Scholarly Projects Collection. https://doi.org/ 10.46409/sr.THBW2378

This Scholarly Project is brought to you for free and open access by the Student Research at SOAR @ USA. It has been accepted for inclusion in Student Scholarly Projects by an authorized administrator of SOAR @ USA. For more information, please contact soar@usa.edu, erobinson@usa.edu. 


\title{
A Patient-Centered Approach to Fall Prevention
}

\author{
Elmer Esguerra, MAN, RN
}

School of Nursing, University of St. Augustine for Health Sciences

This Manuscript Partially Fulfills the Requirements for the

Doctor of Nursing Practice Program and is Approved by:

Camille Payne, $\mathrm{PhD}, \mathrm{RN}$

Candida Constantine, DHA, MBA, MSN, RN, FACHE,

CEN, CPHQ, CPHRM, NEA-BC, HACP, CNML

August 2, 2020 


\section{University of St. Augustine for Health Sciences \\ DNP Scholarly Project \\ Signature Form}

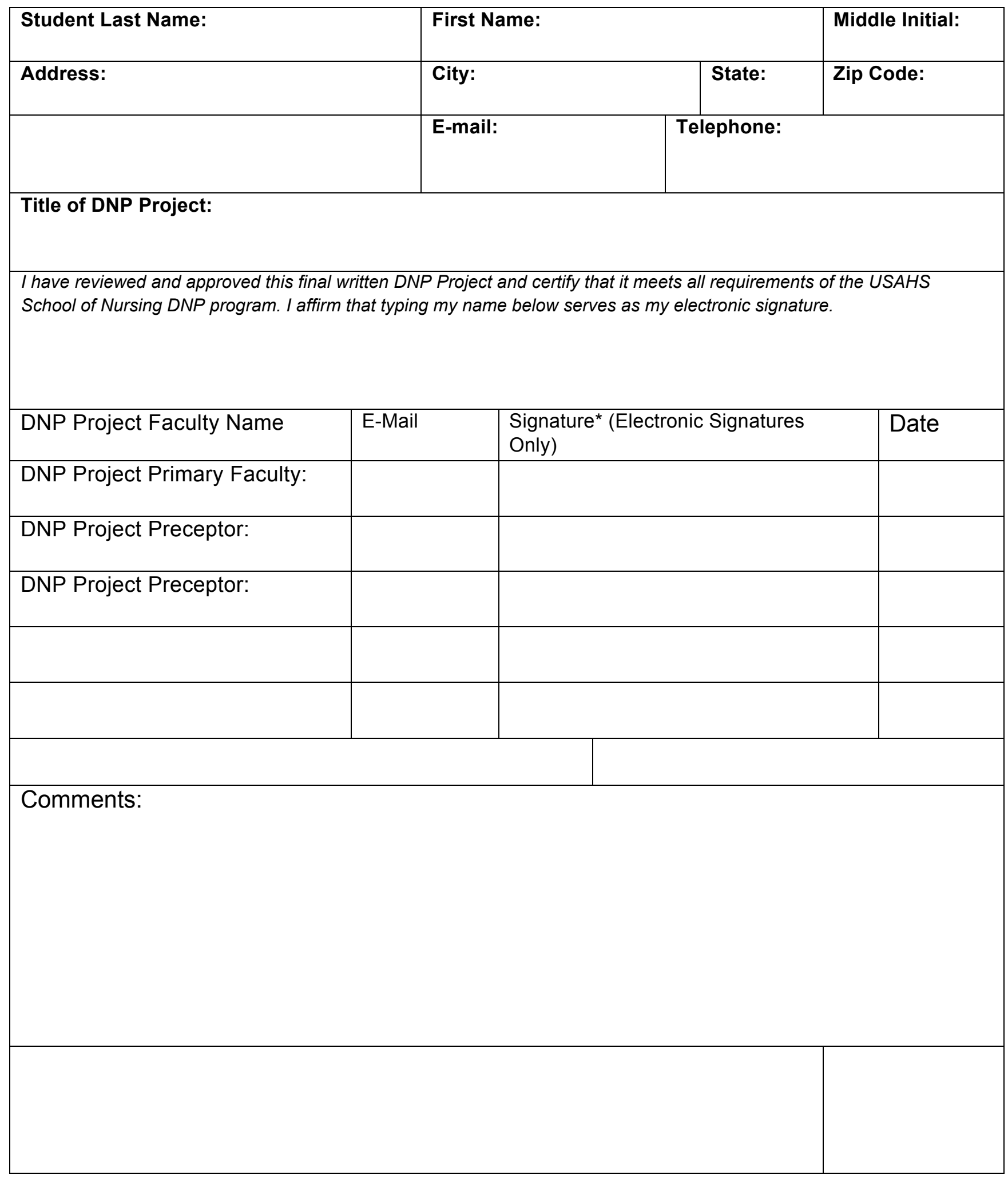




\begin{abstract}
Practice Problem: In 2019, a rural hospital in South Texas reported 102 incidents of patient falls. Although below the corporate fall rate benchmark of 2.2/1000 patient days, the hospital recognized that it was clinically significant and aimed at improving its fall prevention outcomes. PICOT: The PICOT question that guided this project was: Among adult patients in the acute care setting would the implementation of patient-centered interventions be more effective compared to the usual fall prevention interventions in reducing incidence of falls one month after implementation?
\end{abstract}

Evidence: Seven pertinent studies, which included a randomized controlled trial and a systematic review, recommended the implementation of patient-centered fall prevention interventions in reducing fall rates in the acute care setting. The studies supported that patient and family engagement were key in reducing fall incidents in the acute care setting.

Intervention: The evidence-based intervention involved the utilization of a bedside Fall TIPS (Tailoring Interventions for Patient Safety) poster in promoting patient and family engagement in the fall prevention plan to reduce incidents of falls.

Outcome: The project resulted in nurses utilizing the Fall TIPS poster (79\%) in engaging patients in their fall prevention plan through knowledge of their fall risk factors $(80 \%)$ and personalized fall prevention intervention (69\%). There was no reduction in fall rate after 30 days of implementation when compared to the previous year's fall rate of the same month.

Conclusion: Although the project did not result in a reduction of fall rate, the implementation of patient-centered interventions using the Fall TIPS poster promoted patient engagement in the fall prevention process. 


\section{A Patient-Centered Approach to Fall Prevention}

Most hospitals have fall-prevention programs and yet consider high patient fall rates a continuing problem. With the myriad of fall-prevention strategies afforded by evidence, patient falls should no longer be a current concern. However, this is not the case. According to literature, fall prevention protocols have not been applied consistently and interventions aimed to prevent patient falls are far from being standardized (Avanecean, Calliste, Contreras, Lim \& Fitzpatrick, 2017).

\section{Significance of the Practice Problem}

Unintentional patient falls continually concern healthcare institutions on a global level despite the abundance of fall prevention strategies made available in the past several decades (Avanecean et al., 2017). The National Database of Nursing Quality Indicators (NDNQI) defined a patient fall as an "unplanned descent to the floor, with or without injury to the patient" (Agency for Healthcare Research and Quality, 2013). In the United States, it is estimated that the incidence of patient falls in the acute care setting averages 3.3 to 11.5 falls per 1000 patient days (Bouldin et al., 2013). According to Donaldson, Brown, Aydin, Bolton, and Rutledge (2005), $50 \%$ of hospitalized patients in the U.S. are at risk for falls. Thirty to forty percent of falls result in patient injury making it the leading cause of sentinel events. Sentinel events are unexpected occurrences in the healthcare setting leading to death or injury to patients unrelated to the natural course of their illness (Quigley \& White, 2013).

Falls and fall-related injuries greatly impact patients. According to Quigley and White (2013), aside from its physical impact, a fall experience affects a person mentally, socially and emotionally. Moreover, unintentional falls have a negative economic impact on healthcare institutions associated with the added medical cost of treating fall-related injuries and prolonged 
hospital stays (Dunne, Gaboury, \& Ashe, 2014). In 2010, Wu, Keeler, Rubenstein, Maglione and Shekelle estimated the cost of an unintentional fall in three midwestern hospitals respectively: without injury between US $\$ 1,586$-US $\$ 3,500$; with minor injury, US $\$ 9,996-U S \$ 13,316$; and severe injury, US $\$ 24,249$ - US $\$ 27,000$. Additionally, an increased length of stay of 6.3 days per patient with an average cost of US $\$ 14,000$ was linked to fall incidence as reported by Wong, Jones, Waterman, Bolin and Dunagan (2011).

Fall prevention is a main concern among healthcare institutions since providing quality and safe care is their primary goal. As healthcare systems continue to adopt and implement fall prevention strategies, nurses play a critical role in implementing fall prevention procedures in the acute care setting. The hallmark of most fall prevention strategies is risk identification. Although an abundance of risk identification instruments exist, these assessment tools and risk-factor directed interventions are not consistently applied explaining the continued high incidence of falls among adult patients (Avanecean et al., 2017). Moreover, Avanecean et al. (2017) reported that the use of a conventional fall prevention method like the fall risk assessment tool is ineffective in reducing fall rates. Current fall risk scales only address certain intrinsic and extrinsic risk factors and fail to assess the patient's current risk status, thus warranting assessment and intervention that is patient centered (Kulik, 2011). Additionally, Kulik (2011) exerted that for a fall reduction program to be effective, it must provide individualized care, address specific risk factors assessed, and must involve the patient, the patient's family and the interdisciplinary team. The World Health Organization (WHO, 2007) reported that interventions targeting individual risk factors proved to yield the best results in reducing falls, thus the importance of adopting a patientcentered approach in addressing the problem. 


\section{Framework of the Problem}

The person-centered nursing theoretical model, a mid-range theory developed by McCormack and McCance (2006), was used to describe the problem of patient falls and the challenges with fall prevention. The framework consists of four constructs: prerequisites, the care environment; person-centered processes; and expected outcomes.

The prerequisites are focused on the nurses' attributes including professional competence, developed interpersonal skills, commitment to the job, ability to demonstrate clarity of beliefs and values, and knowing oneself (McCormack \& McCance, 2006). Professional competence includes the nurses' knowledge and skills to make decisions, prioritize care, and competence in the technical aspects of care. Commitment includes the nurses' dedication and the sense of motivation to provide the best care to the patient.

The care environment centers on the environment in which care is delivered. This includes the appropriate staffing and skill mix, systems that promote shared decision-making, effective staff relationships, organizational support, power-sharing, and potential for innovation and risktaking (McCormack \& McCance, 2006). Characteristics of this construct include the workplace's culture, the quality of nursing leadership, and the organization's commitment to use multiple sources of evidence in evaluating quality of care delivery.

Person-centered processes are focused on delivering care to the patient by working with the patient's beliefs and values, engaging the patient, having sympathetic presence, shared decision-making, and providing for physical needs (McCormack \& McCance, 2006). Working with the patient's beliefs and values is closely linked to sharing decision-making as nurses facilitate patient participation by providing information and integrating new perspectives into practice. 
Outcomes are the expected results of an effective person-centered nursing, which include patient satisfaction, patients' involvement in care, feeling of well-being, and a therapeutic culture and environment (McCormack \& McCance, 2006). This environment is characterized by collaborative staff relationships, a culture of shared decision-making, leadership that is transformational, and support for innovative practices.

The problem of patient falls and the challenge with fall prevention strategies are grounded in the lack of person-centeredness. The most common reason for a patient's fall in the acute care setting is the patients' reluctance to call for assistance that is influenced by a perception that nurses are too busy (Carroll, Dykes, \& Hurley, 2010; Radecki, Reynolds, \& Kara, 2018). This negative perception by patients arise from the nurses' lack of effective interpersonal skills in conveying a genuine sense of caring and commitment to providing the best patient care (Caroll, Dykes, \& Hurley, 2010). Nurses report a sense of busyness (actual or perceived) due to the pressures of high patient acuity levels, inadequate staffing, assignment overload, and lack of organizational support. As a result, nurses feel isolated to cope with the high demands and pressures of organizational compliance. This leads to staff disengagement and a decreased commitment to do the job.

Fall prevention programs are generally multidisciplinary but are mostly nursing driven due the nurse's role as a patient advocate (Tzeng, 2011). Commonly, when a hospital adopts a new initiative like a fall prevention protocol, it is immediately addressed with staff education. However, training and education is usually not based on evidence and is ineffective in providing nurses with skills to implement the new guideline. Szymaniak (2015) reported in her study that due to a lack of competence in the use of a fall risk screening tool, assessments are inaccurate and inconsistent. Pertinent fall risk factors are overlooked (Szymaniak, 2015), and generic fall 
prevention interventions are implemented in the plan of care that is seldomly communicated to the patient (Tzeng, 2011). When actual risk factors are not accurately identified and communicated, patients do not engage in their fall prevention plan making no effort towards adherence which eventually results in a fall. If not addressed, the process is repeated and becomes a continuous ineffective cycle of implementing fall prevention strategies without the positive outcome of reduced fall incidence.

\section{Scholarly Question}

One 441-bed rural hospital in South Texas, like most U.S. hospitals, share the same challenge of realizing an improvement in the incidence of patient falls. Although the hospital's reported fall rate in 2019 is below the corporate's benchmark of 2.2 falls per 1000 patient days, 99 patient falls remain clinically significant. Reducing the incidence of fall will be beneficial, not only to the facility, but also to patients. This project initially focused on piloting the intervention in three of the adult inpatient medical-surgical units with a plan to disseminate any favorable results to other units and the rest of the facilities in the system. However, due to changes brought by the COVID crisis, the pilot was implemented to only two inpatient units. The PICOT question this project aimed to answer was, "Among adult patients in the acute care setting $(\mathrm{P})$ would the implementation of patient-centered interventions (I) be more effective compared to the usual fall prevention interventions $(\mathrm{C})$ in reducing incidence of falls $(\mathrm{O})$ two months after implementation? (T)" Due to the hospital restrictions related to the COVID pandemic which caused delays in the project implementation, the project evaluation was shortened to 30 days.

\section{Population}

The population of the project consisted of adult patients admitted to two medical-surgical units of a rural hospital in South Texas. Patients who were 18 years and older admitted in these 
units were included in the project.

\section{Intervention}

The intervention consisted of implementing patient-centered fall prevention strategies. According to Avanecean et al. (2017), patient-centered interventions are those directed towards fall risk factors specific to the patient and are geared towards a patient's individual needs, values and preferences. A patient-centered intervention not only considers the patient's needs and preferences but also encourages active patient and family engagement. These patient-focused interventions are intended to be utilized in conjunction with existing organizational fall prevention strategies currently in place. The patient-centered intervention in this project included implementation of accurate fall risk assessments, delivery of a patient-centered fall prevention education to patients and family, and the promotion of patient-engagement activities through patients' self-assessment of fall risk factors and patients' identification of risk-focused fall prevention strategies using the Fall TIPS poster (Dykes et al. (2010) at the bedside as shown in Appendix K \& L.

\section{Comparison}

The intervention was compared to the use of current fall prevention strategies which include the use of the Morse Fall Scale, floor mats, bed/chair alarms, skid proof socks and hourly rounding.

\section{Outcome}

The primary outcome measured in the project was the incidence of falls in the two medical-surgical units of a South Texas hospital. Fall rates were calculated by the number of patient falls per 1000 patient days (Avanecean et al., 2017). A fall is defined as any unintended descent of a patient to the floor, with or without injury (AHRQ, 2013). Data on fall rates were 
obtained from the chairperson of the hospital's Falls Committee responsible for collecting and managing all fall-related data and from the Risk Management department. The aggregated fall rates of the two medical-surgical units were compared with the previous year's fall rate of the same month.

\section{Timing}

Adherence to the intervention was evaluated seven days, 14 days, and 30 days after project implementation. The plan was to sustain any positive outcomes at the practice change setting beyond the project's end and share it with other units and facilities for adoption.

\section{Literature Search Strategy}

Electronic search of digital databases within the University of St. Augustine's library portal included: Cumulative Index to Nursing and Allied Health Literature Complete (CINAHL Complete), ProQuest, and Public/Publisher MEDLINE (PubMed). The keyword and phrase used for the title search in all databases included fall prevention [(fall prevention) OR (individualized fall prevention)]. General limiters applied to all searches included time frame (2014 - 2019), publication type (peer-reviewed), and publication language (English). Inclusion criteria for the title review included: (1) patient-centered or individualized fall prevention strategies were the primary interventions; (2) interventions involved patient and family engagement activities for fall prevention; and (3) primary outcome measures reported were either reduction in fall rate or improved patient and family engagement. Further title and abstract review excluded several articles based on the following exclusion criteria: editorial articles/publications, project sites were in the community or outpatient settings, studies involved pediatric and psychiatric population, and quality improvement projects. A reference review added one article to the list due to its relevance 
to the project's construct. Applying the inclusion and exclusion criteria and removing the duplicates yielded the final list of articles for literature synthesis.

\section{Literature Search Results and Evaluation}

A title search using the keyword and phrase with the application of general limiters resulted in 994 titles from three databases respectively: CINAHL Complete, 264; ProQuest, 396; PubMed, 334. A preliminary title review using the inclusion criteria narrowed the search to 41 articles in CINAHL, 33 in ProQuest, and 37 in PubMed. Full text review using the exclusion criteria and removal of duplicates narrowed the search to six articles. After reviewing the references in the six articles, one article was included which accounted for the seventh article. The PRISMA search model is presented in Appendix A.

Based on the Strength of Recommendation Taxonomy (SORT; Ebbel et al., 2014) guidelines, four quantitative studies provided level three evidence; two random controlled trials (RCTs) at level two; and the systematic review with level one evidence. The strength of recommendation in five of the six studies were Grade A since the recommendations were based on consistent patient-oriented evidence. Individual articles are listed in Appendix C and D. Summary of the systematic review is presented in Appendix E.

\section{Themes from the Literature Review}

The literature review provided evidence addressing the components of the PICOT question which included four quasi-experimental pre/post studies (Duckworth et al., 2019; Dyke et al., 2017; Huang et al., 2015; Opsahl et al., 2017), two randomized control trials (RCTs; Hill et al., 2015; Kiyosho-Teo et al., 2019), and one systematic review of five RCTs (Avanecean et al., 2017). Primary evidence and systematic review tables are presented in Appendix C \& D. Appendix E presents a synthesis matrix of the primary evidences. A thorough evaluation of the 
literature resulted in the identification of themes related to the components of the PICOT question.

\section{Acute Care Setting}

The incidence of patient falls is a widely researched topic and a phenomenon that occurs beyond geographic boundaries. High incidence of patient falls is a problem common to other nations (Hill et al., 2015; Huang et al., 2015). Current healthcare literature abounds with studies on fall incidence and fall prevention strategies for different care settings. Studies are commonly performed in the community setting focused on the elderly population. The change in reimbursement protocol by the Center for Medicare and Medicaid Services (CMS) concerning hospital acquired fall-related injuries in 2008 caused acute care facilities to look closer into their fall prevention strategies (Spetz, Brown, \& Aydin, 2014) since cost to treat these injuries are not reimbursable. Every person in the general community has a certain level of fall risk, and this risk is heightened when a person is hospitalized (Duckworth et al., 2019; Dykes et al., 2017; Opsahl et al., 2017). Experiencing a fall while hospitalized remains a major concern (Hill et al., 2015; Huang et al., 2015; Kiyosho-Teo et al., 2019; Opsahl et al., 2017) which is associated with factors like advanced age, multiple medications, incontinence, visual impairment, weak gait, terminal illness and poor cardiovascular condition (Huang et al., 2015; Opsahl et al, 2017). A similar study by Carroll, Dykes, and Hurley (2010) reported that common perceptions of inpatients as the major reasons for falling included toileting needs and loss of balance with unexpected weakness. They reported that patients were reluctant to call for help because nurses appeared too busy (Carroll, Dykes, \& Hurley, 2010). This is the same observation reported in the study by Dykes, Carroll, Hurley, Benoit, and Middleton (2009) which investigated nurses' and nurse assistants' perception as to why patients fall in the acute care hospitals. The hospital room is a place that is unfamiliar to 
the patients and their families, and an environment that poses a safety risk due to limited space commonly crowded by medical devices and equipment. Patients once hospitalized lose their selfefficacy (Huang et al., 2015; Kiyosho-Teo et al., 2019) in responding to the environment as their senses are altered during the acute phase of their condition.

\section{Patient-Centered Fall Prevention Strategy}

Patient engagement is vital in implementing fall prevention strategies and reducing falls. The healthcare team must recognize that effective patient engagement is based on the foundation of patient-centered care as defined by the Quality and Safety Education for Nurses (QSEN, 2019). Patient-centered care recognizes that the patient or designee is the source of control and an equal participant in the provision of compassionate and coordinated care founded by a respect for patients' preferences, values, and needs.

Patient-centered care is characterized by tailoring interventions specific to patients' needs (Dykes et al., 2017; Hill et al., 2015). Providing individualized patient education and selecting interventions based on identified fall risk factors using a fall prevention poster, were successful in reducing the incidence of in-hospital patient falls (Dykes et al., 2017; Hill et al., 2015). Hill et al. (2015), in a randomized controlled trial, concluded the effectiveness of individualized patient and staff education in reducing the incidence of falls. This was demonstrated by a lower fall rate of 7.8 falls per 1000 patient days and a lower injurious fall rate of 2.63 injurious falls per 1000 patient days in the intervention group compared to 13.78 falls and 4.75 injurious falls per 1000 patient days in the control group.

A patient-centered fall prevention strategy requires accurate fall risk assessment and interventions tailored to patients' needs (Duckworth et al., 2019; Dykes et al., 2017; Huang et al., 2015). A study by Duckworth et al. (2019) and Dykes et al. (2017) showed how staff education 
and training on the Morse Fall Scale improved accuracy of fall risk assessments performed by nurses. Accurate fall risk assessments help facilitate identification of risk factors so they can be eliminated or mitigated (Szymaniak, 2015). Singh and Okeke (2016) presented the positive impact of a systematic nurse training program on fall risk assessment in reducing inpatient falls through a $34 \%$ fall reduction after implementing a systematic nurse training on fall risk assessment.

\section{Patient Engagement Leads to Success of Fall Prevention Plan}

Increasing patient engagement is a pivotal approach in implementing evidence-based fall prevention modalities. Patient engagement is an important component of patient-centeredness (IHI, 2019). According to IHI (2019), patient-centered care places the responsibility for essential aspects of monitoring and self-care in patients' hands. It also requires providing patients the tools and support to carry out this responsibility (IHI, 2019). Current literature supports that patient engagement leads to better health outcomes and contributes to improved patient safety (Tzeng \& Yin, 2015). Incidence of patient falls remains a challenge despite the abundance of fall prevention strategies. Commonly adopted fall prevention protocols in the acute care setting involve interventions that are implemented for and to the patient. Patients have not been treated as partners in fall prevention initiatives. For fall prevention to be patient-centered, patients must take part in its implementation by adhering to the plan.

The incorporation of patient engagement in the fall prevention equation is the focus of five primary evidences reviewed for this project (Duckworth et al., 2019; Dyke et al., 2017; Huang et al., 2015; Kiyosho-Teo, 2019; Opsahl et al., 2017). Patients can be actively involved at different stages of the fall prevention protocol. Active involvement of patients in identifying fall risk factors and specific interventions contribute to fall reduction (Duckworth et al., 2019; Dykes et 
al., 2017). Patients' performance of fall risk self-assessments increases awareness of their fall risk level and encourages active involvement in their safety management (Huang et al., 2015). Patients' active participation in fall education programs improves self-efficacy in implementing fall prevention strategies for their own safety (Huang et al., 2015; Opsahl et al., 2017). A strategy like Motivational Interviewing that actively seeks patients' active involvement in decision-making have been found to increase the frequency of fall prevention behaviors among older inpatients in an RCT conducted by Kiyosho-Teo et al. (2019). When patients take on a partnership role in their safety management, the fall prevention plan becomes a collaborative effort that positions patients and their families in the center and makes the plan effective (Vonnes \& Wolf, 2017).

The literature review provided evidence to answer the PICOT question: Among adult patients in the acute care setting, does implementation of a patient-centered fall prevention intervention compared to usual care, reduce incidence of patient falls within 30 days? Having five (Duckworth et al., 2019; Hill et al., 2015; Huang et al., 2015; Kiyosho-Teo et al., 2019; Opsahl et al., 2017) of the six primary evidences providing Grade A strength of recommendation based on the SORT guidelines, the implementation of a patient-centered fall prevention initiative is geared to help in reducing the incidence of patient falls in selected inpatient units at a South Texas rural hospital.

\section{Practice Recommendations}

Based on the literature synthesis, the recommendation was to implement a patientcentered fall prevention protocol in two inpatient medical-surgical units at a medical center in South Texas to reduce the incidence of patient falls. The patient-centered fall prevention protocol involved nurses' completion of accurate fall risk assessments, provision of individualized fall prevention education to patients and their families, selection of risk-specific interventions 
(Duckworth et al., 2019; Hill et al., 2015), and promoting patient engagement activities (Dykes et al., 2017; Huang et al., 2015; Kiyosho-Teo et al., 2019; Opsahl et al., 2017). Patient engagement activities included patients' self-assessment of risk factors and identification of risk-specific interventions using a laminated bedside fall poster during staff rounding (Duckworth et al., 2019; Dykes et al., 2017). The nursing staff received a refresher training on the use of the Morse Fall Scale to increase accuracy and reliability of fall risk assessments (Dykes et al., 2017; Hill et al., 2015) and training on providing risk-specific fall prevention education to patients and families (Duckworth et al., 2019; Dykes et al., 2017). The nursing staff also received training on how to facilitate patients' self-assessment of fall risk factors and patients' selection of risk-specific fall prevention intervention using the bedside fall poster (Duckworth et al., 2019; Dykes et al., 2017)

\section{Project Setting}

The project was conducted in two medical-surgical units of a 441-bed rural hospital in South Texas. The selected medical-surgical units included 5-East (36 beds) and 7-West (34 beds) consisting of private and semi-private rooms. Patients admitted to these units are adult patients, 18 years old and above, with medical-surgical conditions.

The vision of the hospital is to achieve the "highest level of compassionate care for patients and their families through innovation and advanced technology that is achieved through its mission of providing superior quality healthcare services that patients recommend to their family and friends; physicians prefer for their patients; purchasers select for their clients; employees are proud of; and investors seek for long-term returns" (STHS, 2019). The hospital adopts the Mintzberg's bureaucratic organizational structure having a top-down hierarchical approach in its management practice. The healthcare organization demonstrates a role culture, based on Handy's classification of organizational cultures (Janicijevic, 2017). 
A conversation with the hospital's Chief Nurse Executive (CNE) provided the direction for which problem to consider in this practice change project. Patient falls have been a longstanding challenge as one of the patient safety issues faced by healthcare institutions, including this rural hospital. Data from a recent falls committee report presented that the inpatient units of the hospital, excluding ER and ICU, had a fall rate of 2.2 falls per 1000 patient days in 2019. Although this fall rate is within the corporate's benchmark of 2.2 falls per 1000 patient days, the number reflected 90 incidents of patient falls that are clinically significant, considering its effect on patients' experience and on the institution's quality and financial outcomes. Additionally, the director of Risk Management shared the hospital's top ten list of patient safety issues with patient falls ranking second. The list was generated by the hospital's incident reporting system. Several fall prevention strategies are currently in place at the project site. Strategies included fall risk assessment using the Morse Fall Scale, generation of a fall watch list, use of bed/chair alarms and floor mats, adoption of visual alert devices, environmental risk assessments and proximity and frequent monitoring of patients through hourly rounding. Despite these strategies, the hospital's goal to further reduce the fall rate remained a challenge.

The stakeholders for the practice change project included the nursing department (staff and frontline leaders), ancillary departments, education department, risk management, information systems, public relations department, and mid-level leaders. Leadership and financial support for the project have been extended by the System Chief Nurse Executive. The project sites' unit director has extended full logistic and leadership support. An approved consent to use the hospital setting for the practice change project was obtained from the CEO of the medical center. 
The project included strategies to integrate the proposed intervention into the staff's and facility's work process. It was expected that the project's success is continued beyond its completion. This will be accomplished through annual training and education of frontline leaders, like charge nurses and clinical supervisors, on transformational leadership skills as part of professional development or orientation process. Having frontline leaders with positive influence on the staff's attitude towards adherence with fall prevention strategies is key in hardwiring the desired behavior. Regular and consistent evaluation of the process outcomes through audits provided feedback to leaders and staff that will be helpful in developing performance improvement plans.

This project required collaboration from different disciplines to be successful. Although the nursing staff have the most interaction with the patients, it was important for other disciplines to enforce fall prevention strategies when interacting with the patients and their families. Everyone who interacts with the patient have the responsibility for promoting their safety.

The organization was assessed for internal and external factors that can be considered as facilitators and barriers for implementation. The SWOT (strength, weakness, opportunities, threats) analysis was used to help identify these factors. Organizational strengths identified are strong nursing leadership support; an established policy and procedure on fall prevention; an established fall committee and unit-based fall champions and ambassadors; strong support from other departments; and leadership's heightened awareness of fall's priority as a patient safety issue. Lack of staff engagement and motivation towards fall prevention initiatives, absence of patient and family engagement in the current fall prevention strategies, and lack of motivational skills among frontline leaders to influence staff's adherence to the current fall prevention protocol were among the main weaknesses identified. Two main opportunities identified were the 
utilization of an evidence-based educational strategy for training (on transformational leadership and accurate fall risk assessment) and multidisciplinary engagement with the fall prevention protocol. Identified threats included the legal implications associated with fall-related injuries, negative financial impact on the institution related to treating fall-related injuries and loss of trust from the community. A detailed list of the SWOT analysis is provided in Appendix F.

\section{Project Overview}

The project's vision was to see a decrease in the incidence of falls among adult patients in two medical-surgical units of a rural hospital in South Texas. This vision was accomplished through the project's mission of adopting a patient-centered approach in implementing fall prevention strategies. The use of a patient-centered or individualized approach in fall prevention as recommended by AHRQ is innovative. This is congruent with hospital's vision of achieving the highest quality of compassionate care for patients and their family through innovation, advanced technology, a philosophy of service excellence and visionary leadership. Its mission was to provide superior quality healthcare services that patients recommend to families and friends; physicians prefer for their patients; purchasers prefer for their clients; employees are proud of; and investors seek for long-term returns (South Texas Health System, 2019). The project's vision and mission of promoting patients' safety through decreased incidence of falls aligned with the hospital's vision of providing quality care through innovation that patients will recommend to families and friends.

The project aimed to achieve the following short-term objectives by the end of the 30-day practice change project:

- Completion of training and education by $80 \%$ or more of frontline leaders (charge nurses, fall champions, and clinical supervisors) on transformational leadership skills. 
- Completion of training and education by $80 \%$ or more of nursing and multidisciplinary staff on implementation of patient-centered fall prevention interventions.

- Adherence rate of $80 \%$ or more on implementing patient-centered fall prevention plan of care as evidence by using the Fall TIPS poster at the patient's bedside.

- Adherence rate of $80 \%$ or more on implementing patient and family engagement strategies as evidenced by a completed fall prevention plan poster at the bedside.

- A reduction of $10 \%$ or more in the units' median fall rate as evidenced by documentation in the facility's incident reporting system and report from the facility's Fall Prevention Committee.

The project's long-term objectives included:

- A $20 \%$ or more reduction in the incidence of patient falls for a period of six months and beyond.

- Incorporation of patient-centered fall prevention strategies in the training and competency of the multidisciplinary staff during new employee orientation and annually.

- Implementation of the project in other units and facilities of the health system.

Risks that were identified to be encountered with the project included staff's resistance to change, lack of sustained leadership support, limited budget for staff training, and lack of compliance with implementing a patient-centered fall prevention plan of care.

\section{Project Plan}

The project utilized the Model for Improvement framework developed by the Associates in Process Improvement (API; Langley et al., 2009). According to IHI (2019), this model is not designed to replace the organization's current change model but to accelerate the improvement. 
The framework utilized PDSA (Plan-Do-Study-Act) cycles in testing small scale changes which consists of two parts: the three fundamental questions and the PDSA cycles to test the change and determine whether the change was an improvement (IHI, 2019). The PDSA cycle of the framework aimed at answering three fundamental questions, which are (IHI, 2019):

1. What are we trying to accomplish?

2. How will we know a change is an improvement?

3. What changes can we make that will result in improvement?

The steps in the API's Model for Improvement consisted of forming the team; setting aims; establishing measures; selecting changes; testing the changes; implementing the changes; and spreading the changes (IHI, 2019). The discussion of the project plan will follow the steps of the Model for Improvement.

\section{Forming the Team}

The first step in the process is building the team. The formation of the team is predicated by the identification of the organizational need and the formulation of the PICOT question. The team consisted of the Doctor of Nursing Practice (DNP) student, the student's preceptor, and all identified key stakeholders. Key stakeholders are the nursing staff, nursing frontline leaders, ancillary departments, education department, risk management, information systems, and midlevel leaders. An initial meeting with the key stakeholders was scheduled for a visual presentation of the project proposal. An overview of the project's scope, schedules, timelines, roles \& responsibilities were discussed during the presentation. The DNP student acted as the project manager responsible for coordinating tasks and maintaining a constant flow of communication between members of the implementation team. The student's preceptor, who is also the facility's 
CNE, provided strong leadership, logistic, financial, and human resource support. A table of the budget is presented in Appendix H.

\section{Setting Aims}

With the problem identified in the previous step, the next step focused on identifying the vision, mission, and objectives of the project. This phase answered the first question, "What is being accomplished?" The vision and mission of the project have been established and aligned with that of the facility. Short-term and long-term objectives were formulated. Aside from the goals and objectives, target time frames were identified using a project schedule as shown in Appendix G. The timeline started with the approval of the project proposal by the end of January 2020. The presentation of the project proposal to the key stakeholders and the assignment of roles and responsibilities as well as discussion of schedule and timelines followed. When the timeline was finalized, training and education began. Training was provided to two groups: frontline leaders (charge nurses, clinical supervisors, fall champions, and leaders from other departments) and multidisciplinary staff (nursing, respiratory, physical therapy, laboratory, and dietary). Training of frontline leaders focused on developing transformational leadership skills that will help motivate, encourage, and coach the staff in adhering to the intervention. They were also presented the online education the staff was going to receive which focused on a review of a proper fall risk assessment and the steps in implementing the planned intervention. The frontline leaders consisted of clinical supervisors from the different medical-surgical units at the hospital. Since the staff training and education happened at the height of the COVID-19 surge, staff training was done by completing a self-paced online education delivered through a web-based learning management system. Frontline nursing staff were re-trained on performing accurate fall risk assessments and providing patient/family-centered fall prevention education. The nursing 
staff received training on assessment of patients' knowledge of their fall risk level, risk factor, and the appropriate fall prevention strategy to adopt.

\section{Establishing Measures}

The identification of the process, outcome, balancing, and financial measures were accomplished in this phase. A reduction of $10 \%$ or more in the incidence of patient falls was identified as the outcome measure. Process measures include the staff and leaders' training completion rate, staff's adherence rate to the intervention, and the patients' engagement with the protocol. A target of $80 \%$ or higher for the process measures was established. Random audits, post-fall huddle reports, and EHR review were utilized to gather information related to measures. A data analysis table is presented in Appendix I.

\section{Selecting Changes}

The review of the literature was the basis for selecting the changes implemented in the project. The literature review focused on studies that investigated multiple interventions in preventing patient falls. The concept of patient-centeredness guided the literature search. As common themes were identified from the literature review it became clear that the implementation of a patient-centered fall prevention intervention is the major change that will help reduce the incidence of patient falls in the selected project site. This change consisted of accurate fall risk assessments by RNs, patient education on level of fall risk and associated factors, assessment of the patient's engagement, leaders' training on transformation leadership, and staff's training on patient-centered fall prevention strategies.

\section{Testing the Changes}

Implementation of the selected changes occurred in this phase. After completion of staff training and education, interventions were implemented for 30 days. Nursing staff performed fall 
risk assessment of patients according to hospital policy and provided fall prevention education based on identified risk factors. Nurses educated patients of their fall risk level, risk factors and risk-factor-specific interventions and assessed their knowledge of such information using the Fall TIPS poster as visual aid. Interdisciplinary collaboration was planned for other disciplines (respiratory therapy, physical therapy, social work, case management, laboratory, and dietary) to reinforce the use of the fall TIPS poster at the bedside during their interaction with the patient. However, this was not realized due to COVID-related restrictions limiting movement in hospital units.

As interventions were implemented, observations were made to analyze whether the changes were due to the interventions. To study the process measures, a designated staff performed an audit of nurses' adherence to the use of the Fall TIPS poster in educating patients on their fall risk level, risk factors, and risk-specific interventions. The audit consisted of documentation review and patient interview. Process measures included staff training completion rate and Fall TIPS poster adherence rate obtained on the seventh, 14th, and 30th day post implementation. These data provided useful information for other PDSA cycles that allowed for adjustments to be made in implementing the intervention as deemed necessary.

The project's primary outcome measure of incidence of patient falls was obtained from the chairperson of the hospital's Falls Committee and the Risk Management department.

\section{Implementing the Changes}

Interventions observed to be effective in causing the change were continued. If the intervention was unsuccessful in effecting a change, planning starts again by analyzing what caused the failure in its initial implementation and another PDSA cycle is repeated. Donnelly and 
Kirk (2015) suggested that small progressive changes in complex systems are likely to be successful in producing effective outcomes.

\section{Spreading the Changes}

After analyzing the data peer-reviewed results were shared with the unit and nursing leadership. Because of the COVID-related restrictions on mass gatherings at the time of this project, town hall meetings and huddles were substituted with virtual web meetings.

Barriers to the adoption of the new patient-centered fall prevention culture included lack of awareness to the new practice; lack of familiarity on how to implement the new guideline; lack of agreement with the new practice among staff and leaders; lack of outcome expectancy where staff do not believe that the new practice will positively affect outcomes; lack of staff motivation to depart from previous practice; and lack of reminders to execute the new fall prevention work flow. Facilitators for the adoption of the new practice included strong nursing leadership support by the CNE, existing system-wide fall prevention committee, existing unit-based fall prevention champions and ambassadors, existing fall prevention policy and process in place, and the leadership's awareness that patient falls is a top priority (ranks 2nd) in the organization's list of patient safety issues.

\section{Project Evaluation Plan}

Data related to the process outcomes and primary outcome provided insight to the main variables of the PICOT question. Contextual data included patients' demographics like age and gender. The hospital unit and shift were also considered as contextual elements. These data provided context when interpreting and analyzing the results. The audit form shown in Appendix $\mathrm{J}$ was used to collect these data during random audits. 
The project's process measures consisted of the staff's training completion rate and the staff's adherence rate to the interventions which include adherence to the use of the Fall TIPS poster, assessment of the patients' knowledge of current fall risk level and applicable risk factor, and patient's identification of their personalized fall prevention strategy. Training completion rate was obtained from a report generated by the health institution's web-based learning management system. Staff adherence to the intervention was observed by unit fall champions during random audits, seven, 14, and 30 days after commencement of implementation. The unit fall champions used an audit form (Appendix J) to facilitate consistent collection of data related to adherence. The form prompted the auditor to answer questions related to adherence by choosing from a dichotomous response. The audit addressed whether the RN staff adhered to the new protocol and provided an individualized fall prevention education to the patient and family. The audit further addressed which fall risk factor applied to them and which fall prevention strategy they needed to follow. Auditors obtained answers to these questions through patient interaction. The DNP student discussed the survey form and its use with the unit fall champions to promote consistency in answering the questions promoting inter-rater reliability. To ensure treatment fidelity a target adherence rate of $80 \%$ or above was established for process and sustainability measures.

The project's outcome measure was the incidence of patient falls. The definition of a fall adopted for the project is from The Joint Commission Center for Transforming Healthcare collaborative which is "a sudden, unintentional descent, with or without injury to the patient, which resulted in the patient coming to rest on the floor, on or against some other surface, another person or on an object" (Health Research \& Educational Trust, 2016, p. 6). Incidence of falls in the two inpatient units (5 East and 7 West) were reported as fall rates. A unit's fall rate was calculated by dividing the number of patient falls on a given month by the total number of patient 
days for the same month then multiplied by 1000 . The resulting number indicated the unit's fall rate per 1000 patient days. The calculation of fall rate in relation to patient days is used as recommended by AHRQ since this calculation takes into consideration the number of patients on a given time period. The DNP student collected data related to fall rates from two sources: the hospital's Falls Committee and the Risk Management Department. Using two sources in collecting information related to the primary outcome was important due to the limitation that is inherent in using a single source as identified in literature (Hill et al., 2010). This data collection technique allowed for capturing missing information in the reporting system. The units' aggregated fall rate at 30 days post implementation was compared to the fall rate of the same month from the previous year. Target for the outcome measure is a $10 \%$ or more reduction in the units' fall rate compared to the previous year. Cost savings related to the fall rate reduction constitutes the project's financial measure. The DNP student documented fall related data in a spreadsheet, accessible only by the student and the preceptor. The survey and audit forms did not contain any patient identifiable data. Falls obtained by patients with any psychiatric condition were excluded from this project.

The project implementation commenced after obtaining approval from the school and the facility's administrative leader. To protect patients' privacy and staff's anonymity, survey forms did not contain information linked to patients' and staff's identity.

Descriptive statistics including frequencies, distributions, and measures of central tendencies were utilized in organizing and presenting quantitative data related to the contextual elements which includes the patient's age, gender, hospital unit, and shift. Training completion rate and staff's adherence rate to the process measures were presented using descriptive statistics. 
The units' fall rates were presented using control charts that visually trended the fall rates for a time period.

A chi-square test was used to evaluate the effect of staff training on protocol adherence and the effect of protocol adherence to the patients' knowledge of risk factors and risk-specific interventions. A $P$ value level of .05 or below was used to determine the improvement's statistical significance. The Joint Commission for Transforming Healthcare's definition of zero harm will be the basis for clinical significance. A data analysis table is available as Appendix G.

\section{Evaluation Results}

A total of 32 patients were interviewed during the implementation phase in June 2020. Majority of the patients were male (62\%), age 55 years or older $(53 \%)$ and most of them were from 7 West (75\%) interviewed during the night shift (75\%) who are high fall risk (100\%) as shown in Table 1. The hospital recently updated its fall assessment policy as part of a corporate directive. Patients were assessed for their fall risk level using the Morse Fall Scale (MFS), but rather than categorizing them as low, moderate, or high risk, patients were categorized as either low or high risk for fall. This policy change aimed to streamline fall prevention interventions provided to patients in reducing fall incidents.

Training and education were provided to nurses from the two project sites through a webbased learning management system. Educational training included a review of the MFS criteria and the use of the Fall TIPS poster in promoting patient engagement in their fall prevention plan. Figure 1 shows a staff training and education completion rate of $79 \%$ in 5 East. It further shows that the Fall TIPS poster were used and updated in all patient rooms (100\%), most of the patients knew which fall risk factors applied to them (75\%) and were knowledgeable of their personalized fall prevention plan (75\%). In 7 West, $50 \%$ of the staff completed the required training and 
education. Most of the patients' rooms had the Fall TIPS poster updated (75\%). Additionally, most of the patients interviewed were aware of their fall risk factors $(87 \%)$ and more than half knew their personalized fall prevention plan (62\%) as shown in Figure 2. The process variables were tested using the Chi-square test and revealed no significant relationship as shown in Tables 2,3 , and 4 .

The primary outcome measure of fall rates is presented as individual unit and as an aggregated data shown in Figures 3, 4 and 5. Control charts were used to visually present the trends in fall rates over a time period. The fall rates were plotted on the vertical axis and time was plotted on the horizontal axis from left to right. Healthcare institutions commonly use control charts to study how a process changes over time (AHRQ, 2013). The chart contained plotted historical data, a central line for either the mean or median, an upper line for the upper control limit (UCL), and a lower line for the lower control limit. However, the lower control limit was not included in the charts since zero is the lowest possible number for a fall incident. The charts also included a trendline showing the direction of progress over time and a notation of when the EBP intervention was implemented. The charts present historical fall rates from January 2020 through June 2020 .

The EBP change project was implemented from June 1st through 30th, 2020 in two adult medical-surgical units, namely 5 East and 7 West, at a rural hospital in South Texas. The highest reported fall rate in 5 East was in March 2020 with 6 falls per 1000 patient days and the lowest in May 2020 with zero fall incident with a median rate of 3 falls per 1000 patient days (Figure 4). Fall rate in 7 West was highest in February 2020 at 5.7 falls per 1000 patient days and lowest in March through May 2020 with zero fall incident with the median rate of 0.7 falls per 1000 patient days (Figure 5). The median was used as the centerline instead of the mean due to the skewed 
distribution of fall rates per month (Doring, 2018). The aggregated fall rates of the two units showed a highest rate in February 2020 at 3.9 falls per 1000 patient days and the lowest in May 2020 with zero fall incident. It is evident in the charts that the highest fall rate in both units is below their respective upper control limits whether individually or aggregated. Numerically, both units showed an increase in fall rate from May to June due to an absence of fall incident in the previous month. However, when a trendline was drawn accounting for the pivotal highs and lows from January, fall rates of the two units individually showed contrasting trends: an upward trend in 5 East, and a downward trend in 7 West. Collectively, the aggregated data showed a downward trend in the fall rates.

Table 5 shows a comparison of the fall rates from June 2019 and June 2020. The fall rate in June 2019 increased from 1.29 falls per 1000 patient days to 2.28 falls per 1000 patient days in June 2020, a significant increase of $77 \%$ (0.99 falls per 1000 patient days) from the previous year's fall rate of the same month $(p=<.01)$.

\section{Discussion and Implications}

The primary aim of this project was to increase patient and family engagement in the current fall prevention program in two adult medical-surgical units in a South Texas hospital. The intervention was to supplement ongoing fall prevention interventions by involving the patient and their family in the fall prevention process through education and implementation of patient engagement strategies. The project's intervention focused on using the Fall TIPS poster developed by Dykes et al. (2010) in educating patients on three focus areas: their assessed fall risk level, fall risk factors, and personalized fall prevention interventions. The fall poster was hung in the patient rooms and served as a visual tool in educating patients and/or families and evaluating their understanding of the three focus areas. 
Adherence to the interventions was measured through randomly observing the presence of the poster in patient rooms during audits. The posters were evaluated for their completeness whether they contained correct patient information. The overall adherence with completing the Fall TIPS poster was $81 \%$, similar to a study by Dykes et al. $(2017,2010)$. Adherence to the poster use constituted adherence to the new fall protocol. The director and clinical supervisor of each unit worked closely in actively reminding the nursing staff on updating the Fall TIPS poster in the patients' rooms at least once a shift. An accurate fall risk assessment using the Morse Fall Scale was essential in completing the Fall TIPS poster. As a nurse completed the patient's fall risk assessment, the patient was educated on the three focus areas: identified fall risk level, identified risk factors, and personalized fall prevention interventions. Provision of a personalized fall prevention education aligned with the recommendation in a study by Hill et al. (2015). Patient education was accomplished by using the Fall TIPS poster as a visual aid in enhancing the patient's learning. The nurse circled the appropriate risk factors with the corresponding interventions and shared this information with the patient and/or family. After providing education to the patient, the poster was left hanging in the patients' room. The completion of an accurate fall risk assessment and provision of patient education regarding fall risk level, fall risk factors, and personalized fall prevention interventions using the Fall TIPS poster constituted the first part of the new protocol. This was performed on the patient's admission to the unit or during the initial shift assessment.

The second part of the protocol focused on engaging the patients in the fall prevention process by periodically evaluating their knowledge of the risk factors and the individualized fall prevention interventions. As unit fall champions performed audits on patients identified as high fall risk, patients were asked to identify two things: fall risk factors and fall prevention 
interventions specific to those factors using the Fall TIPS poster. It was expected that patients would know this information from the fall prevention education provided by their primary nurse. Evaluating the patient's knowledge of their fall risk factors and their individualized fall prevention interventions using the Fall TIPS poster constituted the patient engagement strategy which is an important aspect of patient-centeredness (IHI, 2019). As the unit fall champions performed their audits, patients were asked to verbalize the risk factors and the specific fall prevention interventions that applied to them. The auditors evaluated the patients' knowledge by reconciling the patient's stated answers with what was noted in the Fall TIPS poster. When patients failed to answer the questions correctly, the unit fall champions used the Fall TIPS poster to re-educate the patients on the risk factors and individualized interventions. Asking patients to identify the risk factors and interventions on a regular basis reinforced the information to memory as identified in a similar study by Carrol, Dykes, \& Hurley (2010). Actively involving patients to identify their fall risk factors and individualized interventions is key in the success of any fall prevention program (Duckworth et al., 2019; Dykes et al., 2017).

The primary outcome of the project was the reduction in the units' fall rates. The project's interventions were implemented for 30 days beginning June 1st, 2020. June fall rates data from the two units were obtained from the hospital's Falls Committee and Risk Management department to ascertain data reliability. Included in the data were the units' number of falls and the total patient days for June 2019 and 2020. Unit fall rates data were also obtained from January 2020 through June 2020 to examine the fall rates trend considering the project implementation during the month of June. Control charts were used to present the fall rates trend from January to June 2020 in the context of the project implementation. A decreasing trend in the aggregated fall rate was evident in Figure 5. However, Table 2 shows the contrary, where the aggregated fall rate 
of the two units in June 2020 was significantly higher by $77 \%$ compared to the fall rate in June 2019. Thus, the project did not result in a reduction of fall rates as planned like two studies in a systematic review by Avanecean et al. (2017). This may be due to a shortened project implementation timeline from 60 days to 30 days which is a limitation of the project. The originally planned 60-day implementation period was reduced to half due to delays and time constraints caused by restrictions related to the coronavirus pandemic and to meet the DNP student's timeline to complete the project within the course period. Another limitation to the project was the conversion of 5 East to a COVID unit during the implementation phase. This conversion limited the presence of family members and interdisciplinary staff interacting with the patients. With increasing restrictions in the COVID unit, fall champions were not able to perform the audits, which may have negatively affected the amount of reinforcement patients received regarding their individualized fall prevention plan. The restrictions also limited the sample size from that unit which may have contributed to a negative statistical effect. However, despite such restrictions, the full support demonstrated by the CNE, Falls Committee chair, unit director, and the unit fall champions made the project completion possible.

Based on the limitations identified, recommendations for future studies would be a longer implementation period of at least 60 days and collecting three to four months' worth of fallrelated data post implementation. Making the implementation phase longer could possibly increase the adherence to the new protocol and having more data related to fall rates will provide enough information to better identify the relationship of the intervention to the outcome.

Patient-centeredness is key in the provision of patient care. Patient engagement promotes patient-centeredness and is critical in the success of any fall prevention program. Although the project did not result in a statistically significant reduction in fall rates, allowing patients to be 
active participants in their fall prevention plan through engagement strategies remains clinically important.

\section{Dissemination Plan}

Internal dissemination began with the presentation of the project's results to the Chief Nurse Executive who was also my preceptor for review. After obtaining approval from the CNE, the results will be shared with the institution's Falls Committee and the project site unit director. Due to COVID-related restrictions on mass gatherings, project results will be communicated to the nursing staff using a slide presentation uploaded in the institution's web-based learning management system. The unit director may also use this presentation during a regularly scheduled staff meeting. Posters will be used in the common areas of the unit like the staff lounge and meeting room. Brochures will be printed for distribution to the staff.

I would like to submit a manuscript of the scholarly project to the Joint Commission Journal on Quality and Patient Safety. Given the context of the project, it is aligned with the healthcare quality related articles and topics published by this journal and its objectives. Submission of this project to SOAR and the Virginia Henderson Library will also be sought.

\section{Conclusion}

This paper intended to appraise the effectiveness of implementing patient-centered fall prevention interventions in reducing the incidence of patient falls within one month in two inpatient medical-surgical units at a South Texas hospital. Patient falls remain a concern in healthcare organizations and consistent implementation of fall prevention strategies a constant challenge. Evidence support the effectiveness of implementing patient-centered fall prevention interventions in reducing incidence of patient falls in the acute care setting. Promoting active patient engagement in the fall prevention plan of care supports the positive outcome of reduced 
patient falls. Implementing a patient-centered approach and promoting patient engagement in fall prevention is an innovative approach which aligned with the hospital's vision and mission of using innovation in providing quality healthcare services that patients would recommend to their families. The hospital provided full organizational support in equipping the nursing staff and the multidisciplinary team with skills for the implementation of a patient-centered approach in reducing patient falls. 


\section{References}

Agency for Healthcare Research and Quality (2013). Preventing falls in hospitals: How do you measure fall rates and fall prevention practices? Retrieved from https://www.ahrq.gov/professionals/systems/hospital/fallpxtoolkit/fallpxtk5.html

Avanecean, D., Calliste, D., Contreras, T., Yeogyeong Lim, \& Fitzpatrick, A. (2017).

Effectiveness of patient-centered interventions on falls in the acute care setting compared to usual care: A systematic review. JBI Database of Systematic Reviews \& Implementation Reports, 15(12), 3006-3048.

Bouldin, E. L. D., Andresen, E. M., Dunton, N. E., Simon, M., Waters, T. M., Liu, M., ... Shorr, R. I. (2013). Falls among adult patients hospitalized in the United States: Prevalence and trends. Journal of Patient Safety, 9(1), 13-17.

Carroll, D.L., Dykes, P.C., \& Hurley, A.C. (2010). Patients' perspective of falling while in an acute care hospital and suggestions for prevention. Applied Nursing Research, 23(4), 238241.

Donaldson, N., Brown, D.S., Aydin, C.E., Bolton, M.L.B., \& Rutledge, D.N. (2005). Leveraging nurse-related dashboard benchmarks to expedite performance improvement and document excellence. Journal of Nursing Administration, 35(4), 163-172.

Donnelly, P., \& Kirk, P. (2015). Use the PDSA model for effective change management. Education for Primary Care, 26(4), 279-281.

Doring, M. (2018, October 26). Mean vs. median: When to use which measure? Data Science Blog. Retrieved from https://datascienceblog.net/post/basic-statistics/mean_vs_median/

Duckworth, M., Adelman, J., Belategui, K., Feliciano, Z., Jackson, E., Khasnabish, S., ... Dykes, P.C. (2019). Assessing the effectiveness of engaging patients and their families in the 
three-step fall prevention process across modalities of an evidence-based fall prevention toolkit: An implementation science study. Journal of Medical Internet Research, 21(1), e10008.

Dunne, T.J., Gaboury, I., \& Ashe, M.C. (2014). Fall in hospital increase length of stay regardless of degree of harm. Journal of Evaluation in Clinical Practice, 20(2014), 396-400.

Dykes, P.C., Carroll, D.L., Hurley, A.C., Benoit, A., \& Middleton, B. (2009). Why do patients in acute care hospitals fall? Can falls be prevented? Journal of Nursing Administration, 39(6), 299-304.

Dykes, P.C., Carroll, D.L., Hurley, A.C., Lipsitz, S., Benoit, A., Chang, F., ...Middleton, B. (2010). Fall prevention in acute care hospitals: A randomized trial. American Medical Association, 304(17), 1912-1918.

Dykes, P.C., Duckworth, M., Cunningham, S., Dubois, S., Driscoll, M., Feliciano, Z., ...Scanlan, M. (2017). Pilot testing fall TIPS (Tailoring Interventions for Patient Safety): A patientcentered fall prevention toolkit. The Joint Commission Journal on Quality and Patient Safety, 43, 403-413.

Ebell, M. H., Siwek, J., Weiss, B. D., Woolf, S. H., Susman, J., Ewigman, B., \& Bowman, M. (2004). Strength of Recommendation Taxonomy (SORT): A patient-centered approach to grading evidence in the medical literature. The Journal of the American Board of Family Medicine, 17(1), 59-67.

Institute for Healthcare Improvement (2019). Science of improvement: How to improve: Retrieved from www.ihi.org/resources/Pages/HowtoImprove/ScienceofImprovementHowtoImprove.aspx 
Health Research \& Educational Trust. (2016). Preventing patient falls: A systematic approach from the Joint Commission Center for Transforming Healthcare project. Chicago, IL: Health Research \& Educational Trust.

Hill, A-M., Hoffmann, T., Hill, K., Oliver, D., Beer, C., McPhail, S., ... Haines, T.P. (2010). Measuring falls events in acute hospitals-A comparison of three reporting methods to identify missing data in the hospital reporting system. Journal of the American Geriatrics Society, 58(7), 1347-13452.

Hill, A-M., McPhail, S.M., Waldron, N., Etherton-Beer, C., Ingram, K., Flicker, L., ... Haines, T.P. (2015). Fall rates in hospital rehabilitation units after individualized patient and staff education programmes: A pragmatic, stepped-wedge, cluster-randomised controlled trial. The Lancet, 385(9987), 2592-2599.

Huang, L-C., Ma, W-F., Li, T-C., Liang, Y-W, Tsai, L-Y., \& Chang, F-U. (2015). The effectiveness of a participatory program on fall prevention in oncology patients. Health Education Research, 30(2), 298-308.

Institute for Healthcare Improvement (2019). Across the chasm \#3: Health care must be patient centered. Retrieved from www.ihi.org.

Janicijevic, N. (2017). Organizational models as configurations of structure, culture, leadership, control, and change strategy. Economic Annals, 62(213), 67-91.

Kiyosho-Teo, H., Northup-Snyder, K., Cohen, D.J., Dieckmann, N., Stoyles, S., Eckstrom, E., \& Winters-Stone, K. (2019). Feasibility of motivational interviewing to engage older inpatients in fall prevention: A pilot randomized controlled trial. Journal of Gerontological Nursing, 45(9), 19-29. 
Kulik, C. (2011). Components of a comprehensive fall-risk assessment. Special supplement to American Nurse Today - Best practices for falls reduction: A practical guide. Retrieved from: http://americannursetoday.com/special-supplement-to-american-nurse-today-bestpracticesfor-falls-reduction-a-practical-guide/.

Langley, G.L., Nolan, K.M., Nolan, T.W., Norman, C.L., \& Provost, L.P. (2009) The

improvement guide: A practical approach to enhancing organizational performance (2nd ed.). San Francisco, CA: Jossey-Bass Publishers.

Leung, W. Y., Adelman, J., Bates, D. W., Businger, A., Dykes, J. S., Ergai, A., ... Dykes, P. C. (2017). Validating Fall Prevention Icons to Support Patient-Centered Education. Journal of Patient Safety. Retrieved from https://doi.org/10.1097/PTS.0000000000000354

McCormack, B. \& McCance, T.V. (2006). Development of a framework for person-centered nursing. Journal of Advanced Nursing, 56(5), 472-479.

MedCalc (2020). MedCalc Statistical Software (version 19.4.1). Ostend, Belgium: MedCalc Software Ltd. Retrieved from https://www.medcalc.org

Melnyk, B.M. \& Fineout-Overholt, E. (2015). Evidence-based practice in nursing \& healthcare: A guide to best practice (3rd ed.). Philadelphia, PA: Wolters Kluwer Health.

Moher, D., Liberati, A., Tetzlaff, J., Altman, D.G., \& The PRISMA Group (2009). The PRISMA Group preferred reporting items for systematic reviews and meta-analyses: The PRISMA statement. PLoS Med, 6(7): e1000097. https://doi.org/10.1371/journal.pmed.1000097

Opsahl, A.G., Ebright, P., Cangany, M., Lowder, M., Scott, D., \& Shaner, T. (2017). Outcomes of adding patient and family engagement education to fall prevention bundled interventions. Journal of Nursing Care Quality, 32(3), 252-258. 
Quality and Safety Education for Nurses (2019). QSEN competencies. Retrieved from https://qsen.org/competencies/pre-licensure-ksas/\#patient-centered_care

Quigley, P.A., \& White, S.V. (2013). Hospital-based fall program measurement and improvement in high reliability organizations. Online Journal of Issues in Nursing, 18(2), 1.

Radecki, B., Reynolds, S., \& Kara, A. (2018). Inpatient fall prevention from the patients' perspective: A qualitative study. Applied Nursing Research, 43(2018), 114-119.

Singh, I. \& Okeke, J. (2016). Reducing inpatient falls in a 100\% single room elderly care environment: Evaluation of the impact of a systematic nurse training programme on falls risk assessment (FRA). BMJ Quality Improvement Reports, 5(1), 241-256.

South Texas Health System (2019). About South Texas Health System. Retrieved from https://www.southtexashealthsystem.com/about

Spetz, J., Brown, D.S., \& Aydin, C. (2014). The economics of preventing hospital falls: Demonstrating ROI through a simple model. The Journal of Nursing Administration, $45(1), 50-57$.

Szymaniak, S. (2015). Accurate fall risk assessment and interventions for preventing falls in patients in the acute care setting within a private hospital in a large capital city: A best practice implementation project. JBI Database of Systematic Reviews \& Implementation Reports, 13(9), 386-406.

Tzeng, H-M. (2011). Nurses' caring attitude: Fall prevention program implementation as an example of its importance. Nursing Forum, 46(3), 137-145.

Tzeng, H-M. \& Yin, C-Y. (2015). Patient engagement in hospital fall prevention. Nursing Economics, 33(6), 326-334. 
Vonnes, C. \& Wolf, D. (2017). Fall risk and prevention agreement: Engaging patients and families with a partnership for patient safety. BMJ Open Quality, 6, e000038. Doi:10.1136/bmjoq-2017-000038.

Wong, R.C. A. A. J., Jones, M. L., Waterman, B. M., Bollini, M. L., \& Dunagan, W. C. (2011). The cost of serious fall-related injuries at three midwestern hospitals. The Joint Commission Journal on Quality and Patient Safety, 37(2), 81-87.

Wu, S., Keeler, E. B., Rubenstein, L. Z., Maglione, M. A., \& Shekelle, P. G. (2010). A costeffectiveness analysis of a proposed national falls prevention program. Clinics in Geriatric Medicine, 26(4), 751-766. 


\section{Appendix A}

Table 1

Frequency distribution of age, gender, hospital unit, shift, and fall risk level.

\begin{tabular}{|c|c|c|c|c|}
\hline & Frequency & $\%$ & Mean & $\mathrm{SD}$ \\
\hline Age & & & 56.4 & 16.2 \\
\hline Below 55 & 15 & 46.9 & & \\
\hline 55 or above & 17 & 53.1 & & \\
\hline \multicolumn{5}{|l|}{ Gender } \\
\hline Female & 12 & 37.5 & & \\
\hline Male & 20 & 62.5 & & \\
\hline \multicolumn{5}{|l|}{ Hospital Unit } \\
\hline 5 East & 8 & 25.0 & & \\
\hline 7 West & 24 & 75.0 & & \\
\hline \multicolumn{5}{|l|}{ Shift } \\
\hline Day shift & 19 & 59.4 & & \\
\hline Night shift & 24 & 75.0 & & \\
\hline \multicolumn{5}{|c|}{ Morse Fall Risk Level on Interview } \\
\hline High & 32 & 100.0 & & \\
\hline Low & 0 & 0 & & \\
\hline
\end{tabular}

Table 2

Correlation of training of completion rate and adherence to use of Fall TIPS poster

\begin{tabular}{lcc}
\hline & Training Completion Rate & Fall TIPS Poster Adherence \\
\cline { 2 - 3 } Yes & 52 & 26 \\
No & 21 & 6 \\
\hline
\end{tabular}

Note: $X^{2}(1, N=32)=1.2, p=.3$ 
Table 3

Correlation of Fall TIPS poster adherence rate and patients knowledge of risk factors

\begin{tabular}{lcc}
\hline & Fall TIPS Poster Adherence & Patient Knows Risk Factors \\
\cline { 2 - 3 } Yes & 26 & 26 \\
No & 6 & 6 \\
\hline
\end{tabular}

Note: $X^{2}(1, N=32)=0, p=1$

Table 4

Correlation of Fall TIPS poster adherence rate and patients knowledge individual plan

\begin{tabular}{lcc}
\hline & Fall TIPS Poster Adherence & Patient Knows Individual Plan \\
\cline { 2 - 3 } Yes & 26 & 20 \\
No & 6 & 12 \\
\hline
\end{tabular}

Note: $X^{2}(1, N=32)=2.8, p=.09$

Table 5

Aggregated fall rates of 5 East and 7 West compared by dates

June $2019 \quad$ June $2020 \quad$ diff $\quad 95 \%$ CI $\quad$,P-value Incidence

rate ratio

\begin{tabular}{lllllll}
\cline { 2 - 4 } Fate & 1.29 & 2.28 & -0.99 & -1.11 to -0.88 & $<0.01$ & 0.56
\end{tabular}

Note: Fall rate was calculated by dividing the number of falls in a month by the total patient days then multiplying it by 1000 which adjusts for the difference in the number of patients in each unit for a given time (AHRQ, 2013). Incidence rate difference was calculated in MedCalc using Test based Method and the incidence rate ratio using the Exact Poisson Method (MedCalc, 2020) 


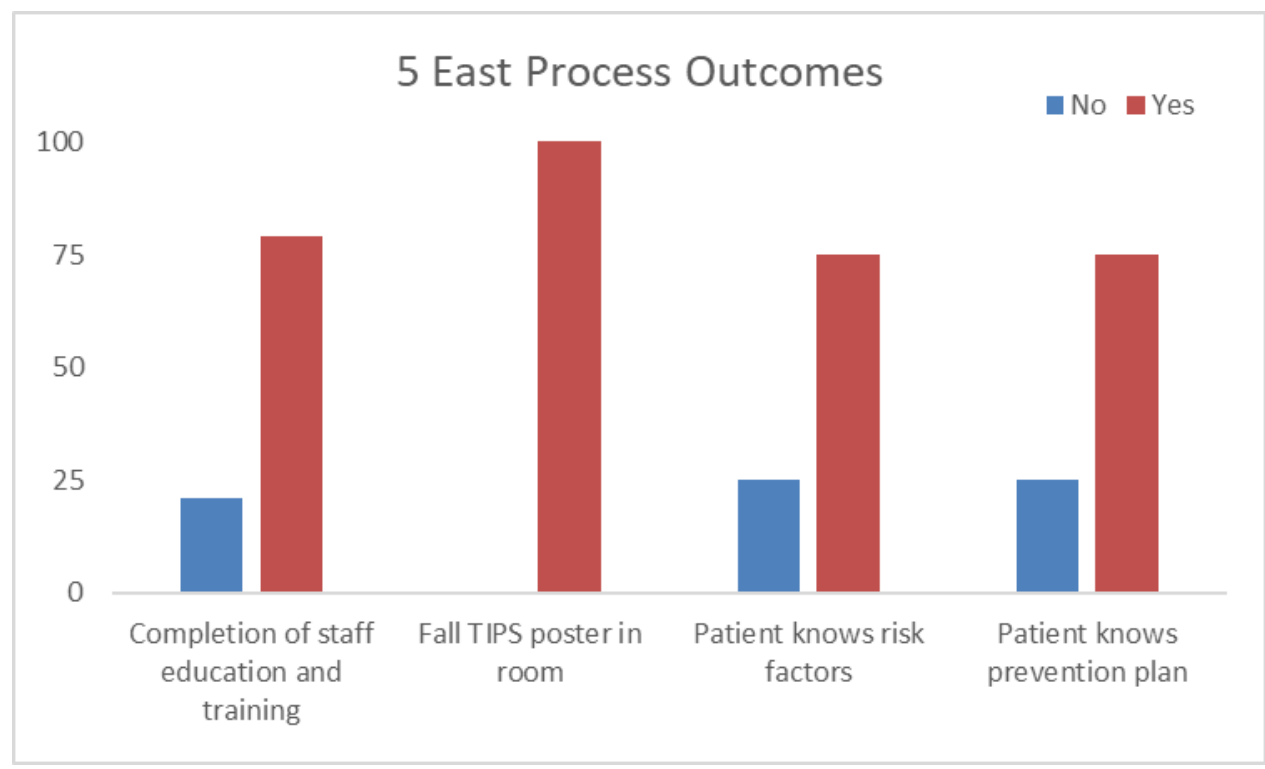

Figure 1. Bar graph showing frequency distribution of the process outcomes for 5 East at McAllen Medical Center.

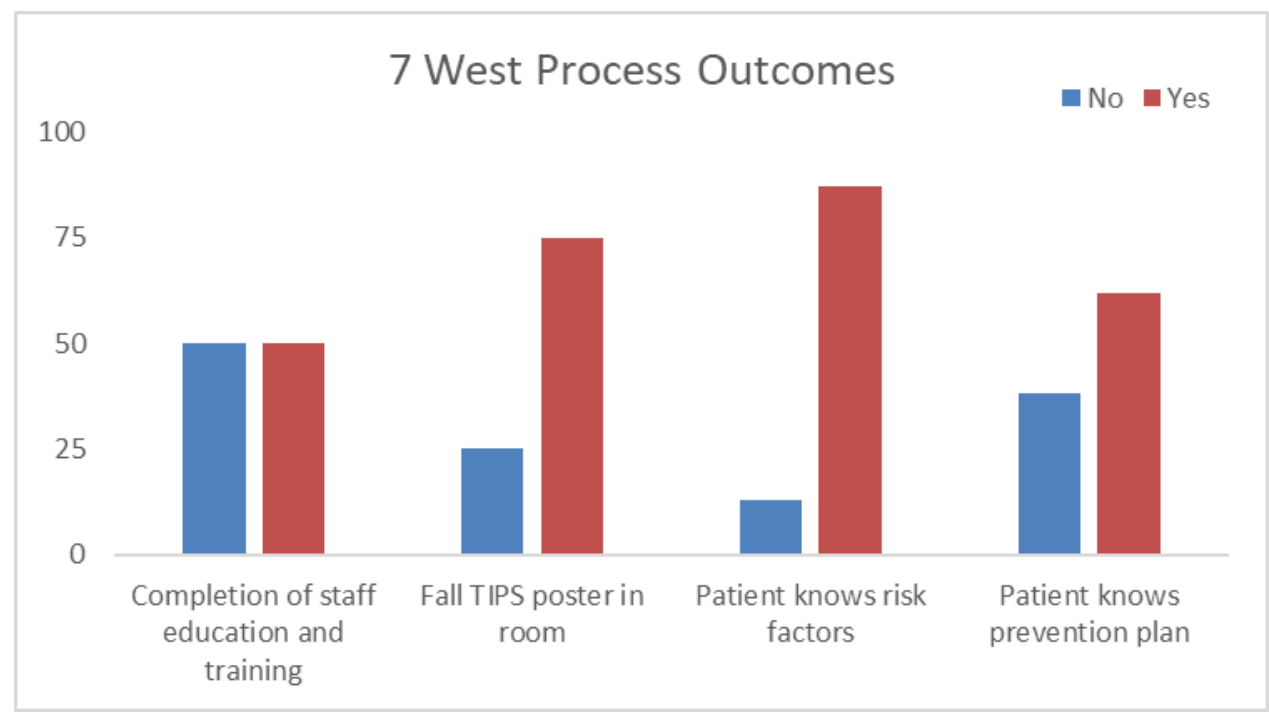

Figure 2. Bar graph showing frequency distribution of the process outcomes for 7 West at McAllen Medical Center 


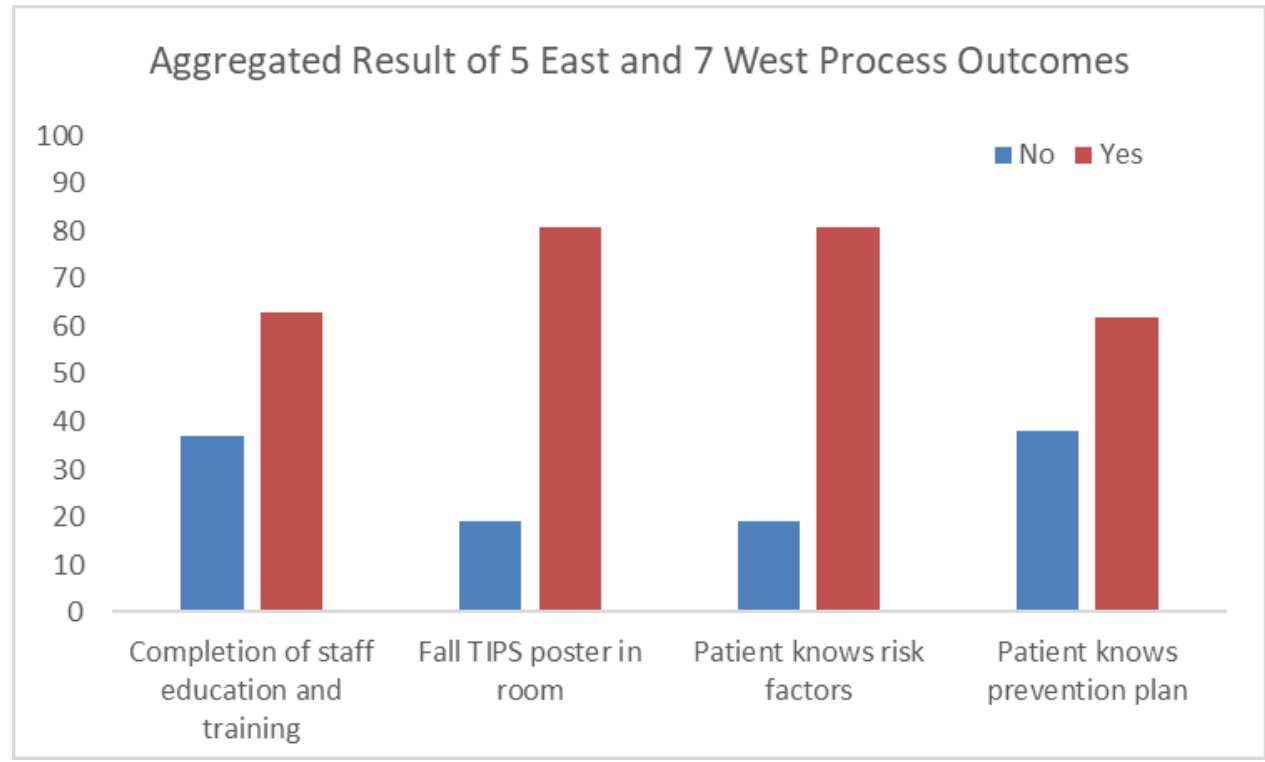

Figure 3. Bar graph showing the aggregated frequency distribution of the process outcomes for 5 East and 7 West at McAllen Medical Center.

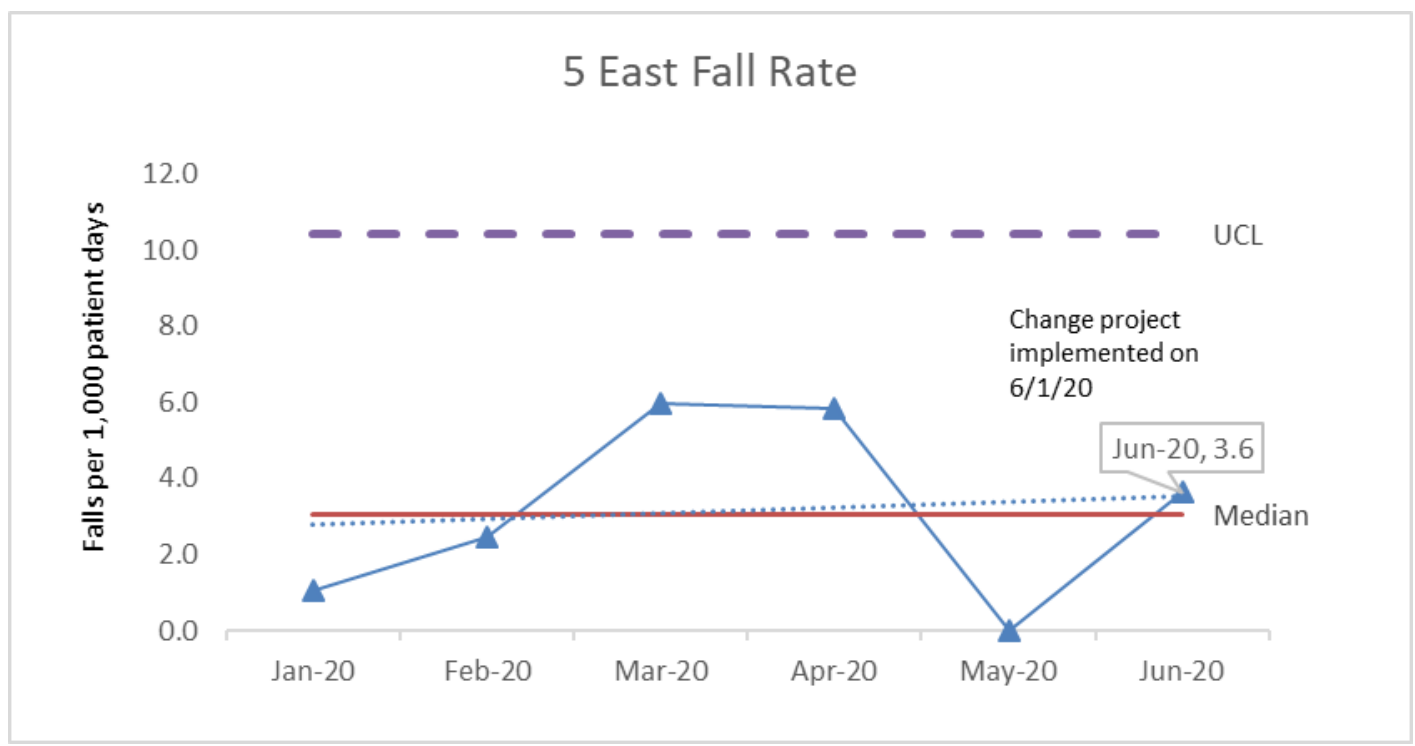

Figure 4. Control chart showing the falls rate per 1000 patient days in 5 East at McAllen Medical Center from January to June 2020 with upper control limit (UCL=10.4), median (3.0), and trend line showing direction of progress. 


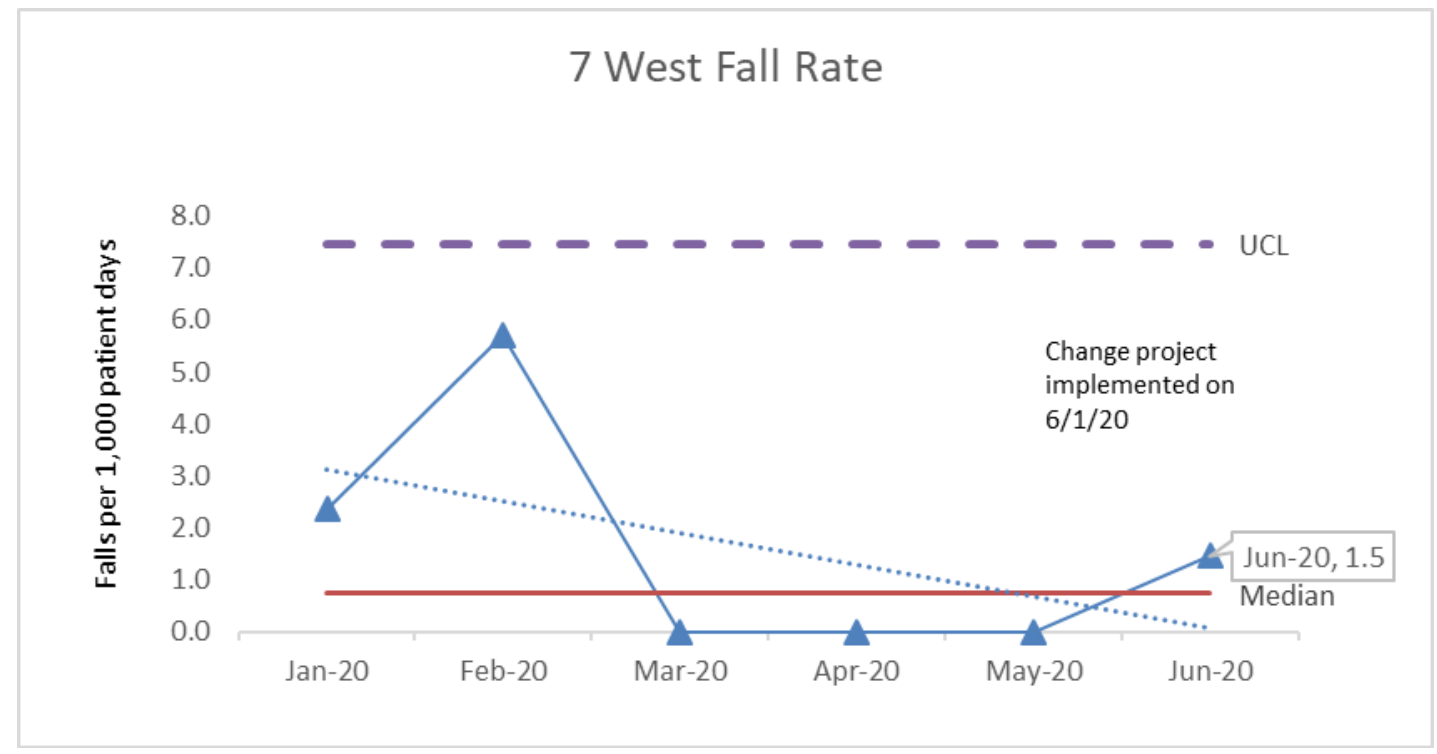

Figure 5. Control chart showing the falls rate per 1000 patient days in 7 West at McAllen Medical Center from January to June 2020 with upper control limit $(\mathrm{UCL}=7.4)$, median $(0.7)$, and trend line showing direction of progress.

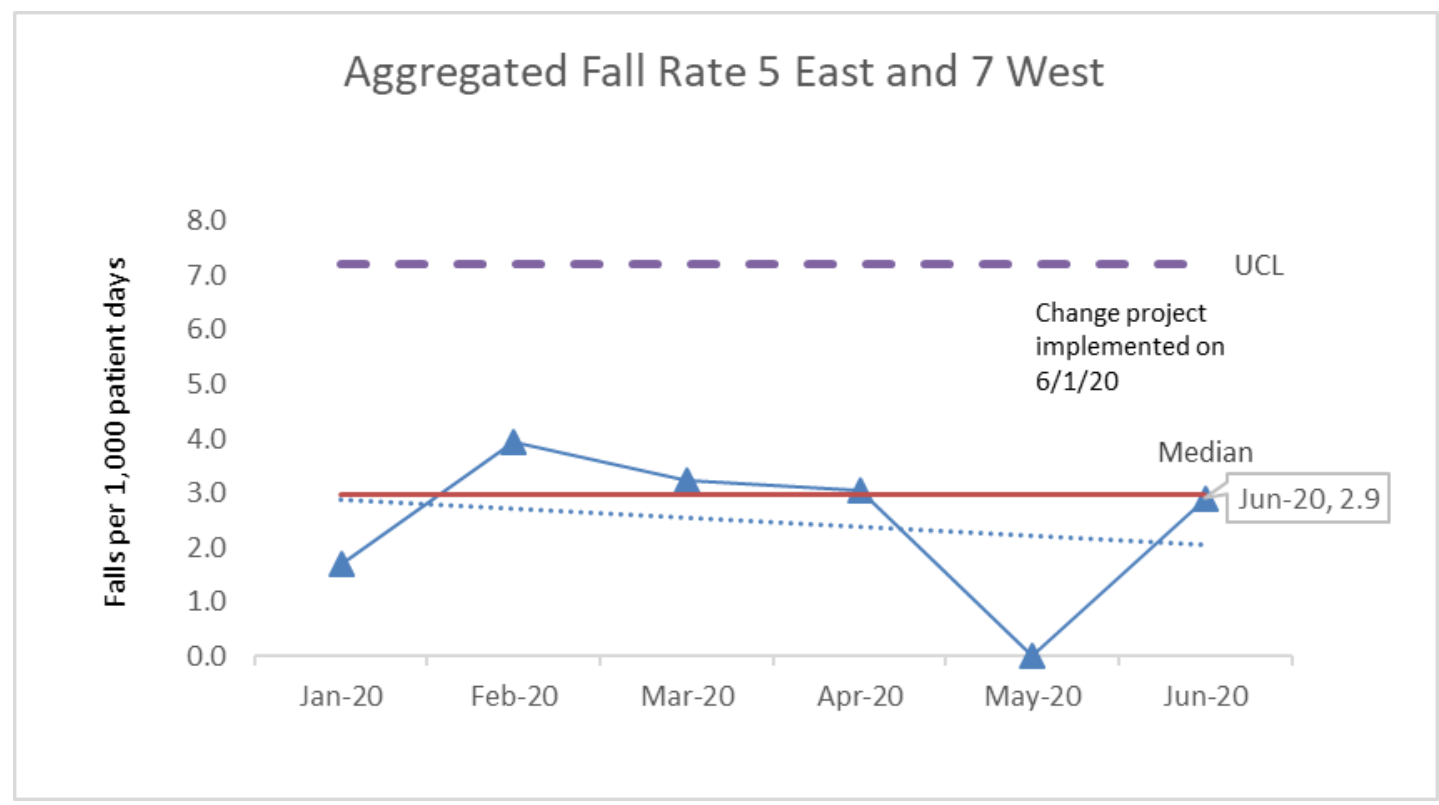

Figure 6. Control chart showing the aggregated falls rate per 1000 patient days 5 East and 7 West at McAllen Medical Center from January to June 2020 with upper control limit (UCL=7.2), median (3.0), and trend line showing direction of progress. 
Appendix B

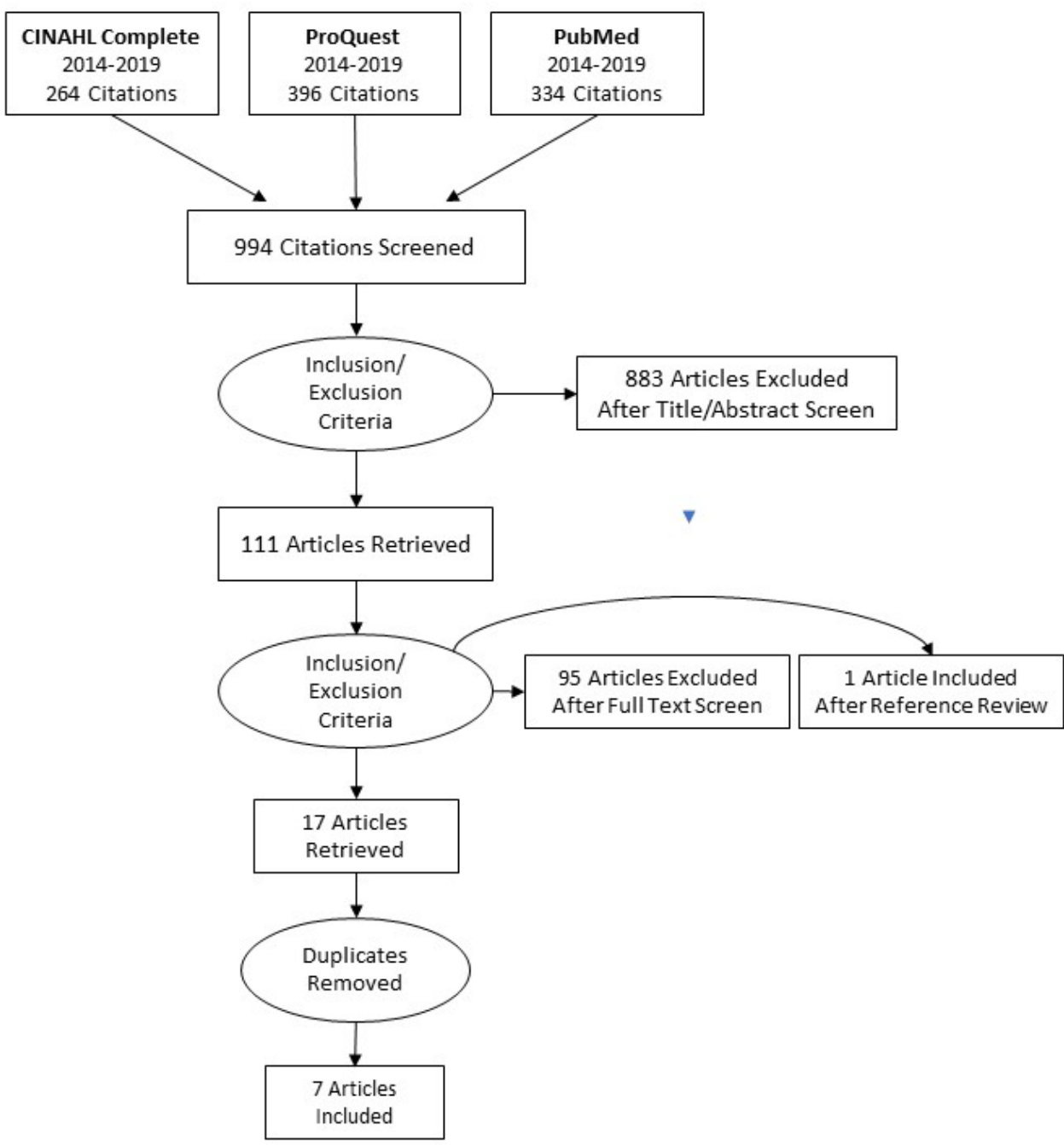

Figure 7. The PRISMA search strategy. (Moher, Liberati, Tetzlaff, \& Altman, 2009) 
Appendix C

Table 6

Summary of Primary Research Evidence

\begin{tabular}{|c|c|c|c|c|c|}
\hline Citation & $\begin{array}{l}\text { Question or } \\
\text { Hypothesis }\end{array}$ & Research Design and Sample Size & Key Findings & $\begin{array}{l}\text { Recommendations/ } \\
\text { Implications }\end{array}$ & $\begin{array}{l}\text { Level of Evidence \& } \\
\text { Strength of } \\
\text { Recommendation }\end{array}$ \\
\hline $\begin{array}{l}\text { Duckworth, M., Adelman, } \\
\text { J., Belategui, K., Feliciano, } \\
\text { Z., Jackson, E., Khasnabish, } \\
\text { S., ... Dykes, P.C. (2019). } \\
\text { Assessing the effectiveness } \\
\text { of engaging patients and } \\
\text { their families in the three- } \\
\text { step fall prevention process } \\
\text { across modalities of an } \\
\text { evidence-based fall } \\
\text { prevention toolkit: An } \\
\text { implementation science } \\
\text { study. Journal of Medical } \\
\text { Internet Research, 21(1), } \\
\text { e10008. }\end{array}$ & $\begin{array}{l}\text { What is the } \\
\text { impact of the } \\
\text { Fall TIPS } \\
\text { modality to } \\
\text { patient } \\
\text { engagement in } \\
\text { the 3-step fall } \\
\text { prevention } \\
\text { process and its } \\
\text { efficacy? }\end{array}$ & $\begin{array}{l}\text { Research Design: A quantitative quasi- } \\
\text { experimental design } \\
\text { Research Tools Used: Random audits were } \\
\text { made to know whether patients and families } \\
\text { knew their fall prevention plan. Additionally, } \\
\text { random audits were conducted to measure } \\
\text { protocol adherence. } \\
\text { Sample Size: A convenience sample of } \\
\text { 5,697 patients across three hospitals from } \\
\text { April to June of } 2017 \text {. } \\
\text { Data Analysis: } \\
\text { Descriptive statistics, frequency percentage. }\end{array}$ & $\begin{array}{l}\text { There was no } \\
\text { significant difference } \\
\text { among the three Fall } \\
\text { TIPS modalities in } \\
\text { engaging patients in the } \\
\text { 3-step fall prevention } \\
\text { process. } \\
\text { Each of Fall TIPS } \\
\text { modality is effective in } \\
\text { engaging patients and } \\
\text { can be used to } \\
\text { implement the evidence } \\
\text { into practice. }\end{array}$ & $\begin{array}{l}\text { Providing three Fall } \\
\text { TIPS modalities is an } \\
\text { effective and flexible } \\
\text { approach for } \\
\text { promoting adoption } \\
\text { and spread of the } \\
\text { evidence-based all } \\
\text { intervention. }\end{array}$ & $\begin{array}{l}\text { Level of Evidence III } \\
\text { Grade A }\end{array}$ \\
\hline $\begin{array}{l}\text { Dykes, P.C., Duckworth, } \\
\text { M., Cunningham, S., } \\
\text { Dubois, S., Driscoll, M., } \\
\text { Feliciano, Z., ...Scanlan, M. } \\
\text { (2017). Pilot testing fall } \\
\text { TIPS (Tailoring } \\
\text { Interventions for Patient } \\
\text { Safety): A patient-centered } \\
\text { fall prevention toolkit. The } \\
\text { Joint Commission Journal } \\
\text { on Quality and Patient } \\
\text { Safety, 43, 403-413. }\end{array}$ & $\begin{array}{l}\text { What strategies } \\
\text { will be } \\
\text { effective in } \\
\text { integrating the } \\
\text { evidence-based } \\
\text { Fall TIPS into } \\
\text { clinical } \\
\text { practice? }\end{array}$ & $\begin{array}{l}\text { Research Design: Pre- and post-test } \\
\text { evaluative approach quasi-experimental } \\
\text { Research Tools Used: Survey, direct } \\
\text { observation, and data extraction } \\
\text { Sample Size: A convenience sample of } 122 \\
\text { patients across eight care units at two } \\
\text { medical centers. } \\
\text { Data Analysis: Independent samples Mann- } \\
\text { Whitney U test to compare Fall TIPS pre- } \\
\text { and post-implementation patient survey. }\end{array}$ & $\begin{array}{l}\text { IHI Framework for } \\
\text { Spread is effective for } \\
\text { implementation and } \\
\text { adoption of innovation } \\
\text { like the Fall TIPS } \\
\text { toolkit. } \\
\text { Identification of } \\
\text { barriers to adoption and } \\
\text { spread of toolkit. }\end{array}$ & $\begin{array}{l}\text { The use of IHI's } \\
\text { Framework for Spread } \\
\text { will help maintain } \\
\text { adoption, sustain } \\
\text { evidence-based fall } \\
\text { prevention practices, } \\
\text { and prevent patient } \\
\text { falls. }\end{array}$ & $\begin{array}{l}\text { Level of Evidence III } \\
\text { Grade B }\end{array}$ \\
\hline $\begin{array}{l}\text { Hill, A-M., McPhail, S.M., } \\
\text { Waldron, N., Etherton-Beer, } \\
\text { C., Ingram, K., Flicker, L., } \\
\text {... Haines, T.P. (2015). Fall }\end{array}$ & $\begin{array}{l}\text { In hospital } \\
\text { rehabilitation } \\
\text { units, does } \\
\text { adding a ward }\end{array}$ & $\begin{array}{l}\text { Research Design: Stepped-wedge cluster } \\
\text { randomized trial. }\end{array}$ & $\begin{array}{l}\text { Individualized fall } \\
\text { prevention education } \\
\text { and staff education } \\
\text { reduced fall rates, }\end{array}$ & $\begin{array}{l}\text { Individualized fall } \\
\text { prevention patient } \\
\text { education be added to }\end{array}$ & $\begin{array}{l}\text { Level of Evidence II } \\
\text { Grade A }\end{array}$ \\
\hline
\end{tabular}




\begin{tabular}{|c|c|c|c|c|c|}
\hline Citation & $\begin{array}{l}\text { Question or } \\
\text { Hypothesis }\end{array}$ & Research Design and Sample Size & Key Findings & $\begin{array}{l}\text { Recommendations/ } \\
\text { Implications }\end{array}$ & $\begin{array}{l}\text { Level of Evidence \& } \\
\text { Strength of } \\
\text { Recommendation }\end{array}$ \\
\hline $\begin{array}{l}\text { rates in hospital } \\
\text { rehabilitation units after } \\
\text { individualized patient and } \\
\text { staff education programmes: } \\
\text { A pragmatic, stepped- } \\
\text { wedge, cluster-randomised } \\
\text { controlled trial. The Lancet, } \\
385(9987), 2592-2599 .\end{array}$ & $\begin{array}{l}\text { level } \\
\text { individualized } \\
\text { fall prevention } \\
\text { education } \\
\text { program to } \\
\text { usual care } \\
\text { reduce patient } \\
\text { falls? }\end{array}$ & $\begin{array}{l}\text { Research Tools Used: Falls data were } \\
\text { collected through data extraction from the } \\
\text { paper-based hospital incident report system } \\
\text { and case notes review. Demographic and } \\
\text { clinical information were collected from the } \\
\text { Quality of Care Register report. } \\
\text { Patient surveys to measure levels of } \\
\text { knowledge, awareness and self-efficacy after } \\
\text { receiving education and to evaluate patient } \\
\text { satisfaction with the education program. } \\
\text { Sample Size: } 3,606 \text { patients in eight general } \\
\text { hospital rehabilitation units in Australia } \\
\text { Data Analysis: All analyses were conducted } \\
\text { on an intention-to-treat basis. Primary } \\
\text { analysis used to compare the rate of falls and } \\
\text { the rate of falls resulting in injury between } \\
\text { the intervention and control period was } \\
\text { negative binomial regression. To compare } \\
\text { the proportion of patients with one or more } \\
\text { falls versus no falls, logistic regression was } \\
\text { used. }\end{array}$ & $\begin{array}{l}\text { injurious falls, and } \\
\text { proportion of patients } \\
\text { who fell compared with } \\
\text { usual care. }\end{array}$ & $\begin{array}{l}\text { usual fall preventive } \\
\text { care. }\end{array}$ & \\
\hline $\begin{array}{l}\text { Huang, L-C., Ma, W-F., Li, } \\
\text { T-C., Liang, Y-W, Tsai, L- } \\
\text { Y., \& Chang, F-U. (2015). } \\
\text { The effectiveness of a } \\
\text { participatory program on fall } \\
\text { prevention in oncology } \\
\text { patients. Health Education } \\
\text { Research, 30(2), 298-308. }\end{array}$ & $\begin{array}{l}\text { Would a fall } \\
\text { prevention } \\
\text { participatory } \\
\text { program be } \\
\text { effective in } \\
\text { reducing fall } \\
\text { incidence rate } \\
\text { among } \\
\text { oncology } \\
\text { patients? }\end{array}$ & $\begin{array}{l}\text { Research Design: Quasi-experimental } \\
\text { single-group pretest and post-test design. } \\
\text { Research Tools Used: Questionnaire } \\
\text { divided into three subscales developed by the } \\
\text { researchers from literature synthesis and } \\
\text { panel discussion. The first subscale assessed } \\
\text { fall risk factor. The second subscale assessed } \\
\text { for fall prevention knowledge and the third } \\
\text { subscale assessed the patients' confidence } \\
\text { regarding fall prevention. } \\
\text { Sample Size: Convenience sampling of } 60 \\
\text { patients admitted to an oncology ward at a } \\
\text { level three medical center in Taiwan. }\end{array}$ & $\begin{array}{l}\text { Patients' knowledge } \\
\text { and self-efficacy on fall } \\
\text { prevention was } \\
\text { increased with a fall } \\
\text { prevention participatory } \\
\text { program. } \\
\text { The difference in fall } \\
\text { incidence between } \\
\text { patients who } \\
\text { participated and those } \\
\text { who did not was } \\
\text { statistically significant. } \\
\text { Fall incidence in the } \\
\text { intervention group was }\end{array}$ & $\begin{array}{l}\text { The provision of fall } \\
\text { prevention } \\
\text { participatory program } \\
\text { can improve care and } \\
\text { prevent avoidable } \\
\text { falls. A well-designed } \\
\text { fall prevention } \\
\text { education increases } \\
\text { patients knowledge on } \\
\text { fall risk factors and } \\
\text { fall prevention } \\
\text { strategies. }\end{array}$ & $\begin{array}{l}\text { Level of Evidence III } \\
\text { Grade A }\end{array}$ \\
\hline
\end{tabular}




\begin{tabular}{|c|c|c|c|c|c|}
\hline Citation & $\begin{array}{l}\text { Question or } \\
\text { Hypothesis }\end{array}$ & Research Design and Sample Size & Key Findings & $\begin{array}{l}\text { Recommendations/ } \\
\text { Implications }\end{array}$ & $\begin{array}{l}\text { Level of Evidence \& } \\
\text { Strength of } \\
\text { Recommendation }\end{array}$ \\
\hline & & $\begin{array}{l}\text { Data Analysis: Descriptive and inferential } \\
\text { statistics. McNemar and paired t-test to } \\
\text { evaluate the FPPP. Z-test was conducted to } \\
\text { compare incidence density rates. }\end{array}$ & $\begin{array}{l}0 \% \text { and } 19.3 \% \text { in the no } \\
\text { intervention group. }\end{array}$ & & \\
\hline $\begin{array}{l}\text { Kiyosho-Teo, H., Northup- } \\
\text { Snyder, K., Cohen, D.J., } \\
\text { Dieckmann, N., Stoyles, S., } \\
\text { Eckstrom, E., \& Winters- } \\
\text { Stone, K. (2019). Feasibility } \\
\text { of motivational interviewing } \\
\text { to engage older inpatients in } \\
\text { fall prevention: A pilot } \\
\text { randomized controlled trial. } \\
\text { Journal of Gerontological } \\
\text { Nursing, 45(9), 19-29. }\end{array}$ & $\begin{array}{l}\text { Is a brief } \\
\text { motivational } \\
\text { interviewing } \\
\text { (MI) feasible } \\
\text { among } \\
\text { hospitalized } \\
\text { Veterans for } \\
\text { fall prevention? } \\
\text { Would a brief } \\
\text { MI be effective } \\
\text { in changing } \\
\text { perceptions and } \\
\text { behaviors of } \\
\text { hospitalized } \\
\text { adults for fall } \\
\text { prevention? }\end{array}$ & $\begin{array}{l}\text { Research Design: Two-arm, unblinded, pilot } \\
\text { randomized controlled trial. } \\
\text { Research Tools Used: Montreal Cognitive } \\
\text { Assessment - Basic (MOCA-B) to survey } \\
\text { participants cognition; Falls Efficacy Scale } \\
\text { International-Short (FESI-S) to assess } \\
\text { participants' fear of falling; Modified Falls } \\
\text { Behavioural (M-FaB-I) Scale-Inpatient to } \\
\text { assess participants' fall prevention daily } \\
\text { behaviors; Patient Activation Measure } \\
\text { (PAM) to assess level of engagement with } \\
\text { participants' own health; Chart review for } \\
\text { baseline demographics variables; and the } \\
\text { AHRQ High Fall Risk Medication Score to } \\
\text { assess fall risk due to medications. } \\
\text { Sample Size: } \\
\text { Convenience sampling of } 67 \text { patients. } \\
\text { Data Analysis: } \\
\text { Descriptive analysis using frequencies and } \\
\text { distributions. Two-tailed t-tests to compare } \\
\text { groups. Partial correlations were used to } \\
\text { identify relationships between fall perception } \\
\text { and behavior measures. }\end{array}$ & $\begin{array}{l}\text { Experience of recent } \\
\text { falls and injurious falls } \\
\text { were associated with } \\
\text { increased } \\
\text { demonstration of fall } \\
\text { prevention activities. } \\
\text { Perceptions related to } \\
\text { fall prevention were } \\
\text { positively associated } \\
\text { with frequency of fall } \\
\text { prevention behaviors. } \\
\text { Use of FaB-I revealed } \\
\text { that patients were } \\
\text { reluctant to use the call } \\
\text { light and talk about fall } \\
\text { prevention and may } \\
\text { hurry to use the toilet. }\end{array}$ & $\begin{array}{l}\text { The use FESI-S, PAM, } \\
\text { confidence and } \\
\text { importance ratings, } \\
\text { and FaB-I can be } \\
\text { useful in enhancing } \\
\text { patient engagement } \\
\text { with fall prevention } \\
\text { and may be beneficial } \\
\text { if added to existing } \\
\text { fall prevention } \\
\text { programs. }\end{array}$ & $\begin{array}{l}\text { Level of Evidence II } \\
\text { Grade A }\end{array}$ \\
\hline $\begin{array}{l}\text { Opsahl, A.G., Ebright, P., } \\
\text { Cangany, M., Lowder, M., } \\
\text { Scott, D., \& Shaner T. } \\
\text { (2017). Outcomes of adding } \\
\text { patient and family } \\
\text { engagement education to fall } \\
\text { prevention bundled } \\
\text { interventions. Journal of }\end{array}$ & $\begin{array}{l}\text { What is the } \\
\text { impact of an } \\
\text { educational } \\
\text { video } \\
\text { intervention for } \\
\text { patients and } \\
\text { their families } \\
\text { when added to } \\
\text { current fall }\end{array}$ & $\begin{array}{l}\text { Research Design: Quasi-experimental, } \\
\text { pre/posttest design. } \\
\text { Research Tools Used: Patient fall data were } \\
\text { collected from the hospital computerized } \\
\text { incident recording software and abstraction } \\
\text { of EHR. EHR review to collect demographic } \\
\text { and clinical characteristics of the patients. }\end{array}$ & $\begin{array}{l}\text { Fall incidence during } \\
\text { the implementation } \\
\text { period was at } 0.88 \text { falls } \\
\text { per } 1000 \text { patient days in } \\
\text { the orthopedic unit and } \\
1.2 \text { falls per } 1000 \\
\text { patient days in the } \\
\text { medical-surgical unit. } \\
\text { This is a reduction from }\end{array}$ & $\begin{array}{l}\text { Addition of fall } \\
\text { prevention educational } \\
\text { video for patients and } \\
\text { families can have } \\
\text { positive trend toward } \\
\text { decreasing the fall rate } \\
\text { in the acute care } \\
\text { setting. The video } \\
\text { intervention provides }\end{array}$ & $\begin{array}{l}\text { Level of Evidence III } \\
\text { Grade A }\end{array}$ \\
\hline
\end{tabular}




\begin{tabular}{|c|c|c|c|c|c|}
\hline Citation & $\begin{array}{l}\text { Question or } \\
\text { Hypothesis }\end{array}$ & Research Design and Sample Size & Key Findings & $\begin{array}{l}\text { Recommendations/ } \\
\text { Implications }\end{array}$ & $\begin{array}{l}\text { Level of Evidence } \& \\
\text { Strength of } \\
\text { Recommendation }\end{array}$ \\
\hline $\begin{array}{l}\text { Nursing Care Quality, } \\
32(3), 252-258 .\end{array}$ & $\begin{array}{l}\text { prevention } \\
\text { bundled } \\
\text { interventions? }\end{array}$ & $\begin{array}{l}\text { Staff survey to determine perception of the } \\
\text { intervention. } \\
\text { Sample Size: } \\
\text { Convenience sampling of } 2148 \text { patients. } \\
\text { Data Analysis: } \\
\text { Measures of central tendencies used for } \\
\text { demographics, fall rates, and length of stay. } \\
\text { Frequencies and distribution for staff's } \\
\text { compliance on viewing educational video. }\end{array}$ & $\begin{array}{l}\text { the } 2.86 \text { and } 3.27 \text { falls } \\
\text { per } 1000 \text { patients days } \\
\text { in the respective units } \\
\text { during the pre- } \\
\text { implementation period. }\end{array}$ & $\begin{array}{l}\text { the patients and } \\
\text { families an } \\
\text { opportunity to engage } \\
\text { in the discussion and } \\
\text { education of fall } \\
\text { prevention. }\end{array}$ & \\
\hline
\end{tabular}


Appendix D

Table 7

Summary of Systematic Reviews

\begin{tabular}{|c|c|c|c|c|c|c|c|}
\hline Citation & Question & Search Strategy & $\begin{array}{l}\text { Inclusion/ } \\
\text { Exclusion } \\
\text { Criteria }\end{array}$ & $\begin{array}{l}\text { Data Extraction and } \\
\text { Analysis }\end{array}$ & Key Findings & $\begin{array}{l}\text { Recommendation/ } \\
\text { Implications }\end{array}$ & $\begin{array}{l}\text { Level of } \\
\text { Evidence \& } \\
\text { Strength of } \\
\text { Recommendati } \\
\text { on }\end{array}$ \\
\hline $\begin{array}{l}\text { Avanacean, D., } \\
\text { Calliste, D., } \\
\text { Contreras, T., } \\
\text { Lim, Y., \& } \\
\text { Fitzpatrick, A. } \\
\text { (2017). } \\
\text { Effectiveness of } \\
\text { patient-centered } \\
\text { interventions on } \\
\text { falls in the acute } \\
\text { care setting } \\
\text { compared to } \\
\text { usual care: A } \\
\text { systematic } \\
\text { review. JBI } \\
\text { Database of } \\
\text { Systematic } \\
\text { Reviews and } \\
\text { Implementation } \\
\text { Reports, 15(12), } \\
\text { 3006-3048. }\end{array}$ & $\begin{array}{l}\text { Evaluate the } \\
\text { effectiveness of } \\
\text { patient-centered } \\
\text { interventions on } \\
\text { falls in the acute } \\
\text { care setting }\end{array}$ & $\begin{array}{l}\text { Comprehensive search } \\
\text { for published and } \\
\text { unpublished } \\
\text { quantitative, English } \\
\text { studies from inception } \\
\text { of databases through } \\
\text { July } 30,2016 . \\
\text { Databases include } \\
\text { PubMed, CINAHL, } \\
\text { Embase and Health } \\
\text { Source: } \\
\text { Nursing/Academic } \\
\text { Edition. ProQuest } \\
\text { Dissertations and } \\
\text { Theses, New York } \\
\text { Academy of Medicine, } \\
\text { and Virginia Henderson } \\
\text { e-Repository to search } \\
\text { for unpublished studies. } \\
\text { Initial keywords used: } \\
\text { acute care, hospital, } \\
\text { patient-centered care, } \\
\text { falls, and fall } \\
\text { prevention. }\end{array}$ & $\begin{array}{l}\text { Inclusion } \\
\text { criteria: Adult } \\
\text { patients admitted } \\
\text { to medical or } \\
\text { surgical acute } \\
\text { care; patient- } \\
\text { centered } \\
\text { intervention } \\
\text { strategies to } \\
\text { reduce falls; } \\
\text { randomized } \\
\text { controlled trials; } \\
\text { primary outcome } \\
\text { is fall rate or } \\
\text { number of falls } \\
\text { Exclusion } \\
\text { criteria: studies } \\
\text { with non-patient- } \\
\text { centered } \\
\text { interventions } \\
\text { were excluded } \\
\text { from the review. }\end{array}$ & $\begin{array}{l}\text { Quantitative data were } \\
\text { extracted by four } \\
\text { independent reviewers } \\
\text { using the JBI-SUMARI } \\
\text { data extraction tool. } \\
\text { The data extracted from } \\
\text { the studies included the } \\
\text { population, number of } \\
\text { participants, city and } \\
\text { country of origin, } \\
\text { languages of patient } \\
\text { education materials, } \\
\text { nursing unit type, } \\
\text { interventions, } \\
\text { methodology, and } \\
\text { measured outcomes. } \\
\text { Disagreements that } \\
\text { arose between } \\
\text { reviewers were resolved } \\
\text { through discussion. }\end{array}$ & $\begin{array}{l}\text { Three out of the } \\
\text { five included } \\
\text { studies concluded } \\
\text { that there was a } \\
\text { reduction in fall } \\
\text { rates when } \\
\text { implementing } \\
\text { patient-centered } \\
\text { fall prevention } \\
\text { interventions in } \\
\text { acute care } \\
\text { hospitals. }\end{array}$ & $\begin{array}{l}\text { Healthcare settings } \\
\text { should consider } \\
\text { implementing a } \\
\text { more patient- } \\
\text { centered approach } \\
\text { to fall prevention. } \\
\text { The use of unit- } \\
\text { based fall } \\
\text { champions may } \\
\text { help in reducing } \\
\text { falls. }\end{array}$ & $\begin{array}{l}\text { Level of } \\
\text { Evidence I } \\
\text { Grade B }\end{array}$ \\
\hline
\end{tabular}


Table 8

Appendix E

\section{Evidence Synthesis Matrix}

\begin{tabular}{|c|c|c|c|c|c|c|}
\hline Main ideas & $\begin{array}{l}\text { Reference 1 } \\
\text { Duckworth, M., } \\
\text { Adelman, J., Belategui, } \\
\text { K., Feliciano, Z., } \\
\text { Jackson, E., Khasnabish, } \\
\text { S., ... Dykes, P.C. } \\
\text { (2019). Assessing the } \\
\text { effectiveness of } \\
\text { engaging patients and } \\
\text { their families in the } \\
\text { three-step fall prevention } \\
\text { process across modalities } \\
\text { of an evidence-based fall } \\
\text { prevention toolkit: An } \\
\text { implementation science } \\
\text { study. Journal of } \\
\text { Medical Internet } \\
\text { Research, 21(1), e10008. }\end{array}$ & $\begin{array}{l}\text { Reference } 2 \\
\text { Dykes, P.C., Duckworth, } \\
\text { M., Cunningham, S., } \\
\text { Dubois, S., Driscoll, M., } \\
\text { Feliciano, Z., ... Scanlan, } \\
\text { M. (2017). Pilot testing } \\
\text { fall TIPS (Tailoring } \\
\text { Interventions for Patient } \\
\text { Safety): A patient- } \\
\text { centered fall prevention } \\
\text { toolkit. The Joint } \\
\text { Commission Journal on } \\
\text { Quality and Patient } \\
\text { Safety, 43, 403-413. }\end{array}$ & $\begin{array}{l}\text { Reference } 3 \\
\text { Hill, A-M., McPhail, } \\
\text { S.M., Waldron, N., } \\
\text { Etherton-Beer, C., } \\
\text { Ingram, K., Flicker, L., } \\
\text {.. Haines, T.P. (2015). } \\
\text { Fall rates in hospital } \\
\text { rehabilitation units after } \\
\text { individualized patient } \\
\text { and staff education } \\
\text { programmes: A } \\
\text { pragmatic, stepped- } \\
\text { wedge, cluster- } \\
\text { randomised controlled } \\
\text { trial. The Lancet, } \\
\text { 385(9987), 2592-2599. }\end{array}$ & $\begin{array}{l}\text { Reference } 4 \\
\text { Huang, L-C., } \\
\text { Ma, W-F., Li, T- } \\
\text { C., Liang, Y-W, } \\
\text { Tsai, L-Y., \& } \\
\text { Chang, F-U. } \\
\text { (2015). The } \\
\text { effectiveness of } \\
\text { a participatory } \\
\text { program on fall } \\
\text { prevention in } \\
\text { oncology } \\
\text { patients. Health } \\
\text { Education } \\
\text { Research, 30(2), } \\
\text { 298-308. }\end{array}$ & $\begin{array}{l}\text { Reference } 5 \\
\text { Kiyosho-Teo, H., Northup- } \\
\text { Snyder, K., Cohen, D.J., } \\
\text { Dieckmann, N., Stoyles, S., } \\
\text { Eckstrom, E., \& Winters- } \\
\text { Stone, K. (2019). } \\
\text { Feasibility of motivational } \\
\text { interviewing to engage } \\
\text { older inpatients in fall } \\
\text { prevention: A pilot } \\
\text { randomized controlled trial. } \\
\text { Journal of Gerontological } \\
\text { Nursing, 45(9), 19-29. }\end{array}$ & $\begin{array}{l}\text { Reference } 6 \\
\text { Opsahl, A.G., Ebright, } \\
\text { P., Cangany, M., } \\
\text { Lowder, M., Scott, D., } \\
\text { \& Shaner T. (2017). } \\
\text { Outcomes of adding } \\
\text { patient and family } \\
\text { engagement education } \\
\text { to fall prevention } \\
\text { bundled interventions. } \\
\text { Journal of Nursing } \\
\text { Care Quality, 32(3), } \\
\text { 252-258. }\end{array}$ \\
\hline Setting & $\begin{array}{l}\text { Neurology and Medical } \\
\text { Units - Northeast US }\end{array}$ & $\begin{array}{l}\text { Neuroscience } \\
\text { Intermediate, Medical } \\
\text { Intermediate, Oncology, } \\
\text { Medical Intermediate - } \\
\text { Northeast US }\end{array}$ & $\begin{array}{l}\text { Rehabilitation } \\
\text { Unit/Inpatient - } \\
\text { Australia }\end{array}$ & $\begin{array}{l}\text { Oncology } \\
\text { Unit/Inpatient - } \\
\text { Taiwan }\end{array}$ & $\begin{array}{l}\text { Medical-Surgical units- VA } \\
\text { Hospital Northwestern US }\end{array}$ & $\begin{array}{l}\text { Orthopedic and } \\
\text { Medical-Surgical units } \\
\text { - Midwest US }\end{array}$ \\
\hline $\begin{array}{l}\text { Patient- } \\
\text { centered fall } \\
\text { interventions }\end{array}$ & $\begin{array}{l}\text { Evaluating the three } \\
\text { modalities of the Fall } \\
\text { TIPS toolkit }\end{array}$ & $\begin{array}{l}\text { The use of the Fall TIPS } \\
\text { toolkit (FTTK) promotes } \\
\text { individualized risk } \\
\text { assessment and fall } \\
\text { prevention intervention }\end{array}$ & $\begin{array}{l}\text { Individualized patient } \\
\text { education on fall } \\
\text { prevention }\end{array}$ & & & $\begin{array}{l}\text { Fall prevention } \\
\text { education video as } \\
\text { intervention }\end{array}$ \\
\hline $\begin{array}{l}\text { Patient and } \\
\text { family } \\
\text { engagement }\end{array}$ & $\begin{array}{l}\text { Engaging patients and } \\
\text { families in the } 3 \text {-step fall } \\
\text { prevention process }\end{array}$ & $\begin{array}{l}\text { Using the FTTK } \\
\text { promotes patient and } \\
\text { family engagement in } \\
\text { fall prevention strategies }\end{array}$ & & $\begin{array}{l}\text { Introduction of a } \\
\text { fall prevention } \\
\text { participatory } \\
\text { program }\end{array}$ & $\begin{array}{l}\text { Motivational interviewing } \\
\text { promotes patient } \\
\text { engagement in fall } \\
\text { prevention activities }\end{array}$ & $\begin{array}{l}\text { Fall prevention video } \\
\text { promotes patient and } \\
\text { family engagement }\end{array}$ \\
\hline $\begin{array}{l}\text { Primary } \\
\text { outcome }\end{array}$ & $\begin{array}{l}\text { Increased patient and } \\
\text { family engagement }\end{array}$ & $\begin{array}{l}\text { Increased adoption of } \\
\text { toolkit with the use of } \\
\text { IHI's Framework for } \\
\text { Spread. }\end{array}$ & $\begin{array}{l}\text { Reduced fall rate and } \\
\text { injurious falls }\end{array}$ & $\begin{array}{l}\text { Reduced } \\
\text { incidence of } \\
\text { falls }\end{array}$ & $\begin{array}{l}\text { Increase patient } \\
\text { engagement with fall } \\
\text { prevention activities with } \\
\text { motivational interview }\end{array}$ & $\begin{array}{l}\text { Significant reduction in } \\
\text { fall rates }\end{array}$ \\
\hline
\end{tabular}


Appendix F

Table 9

SWOT ANALYSIS

\begin{tabular}{|c|c|}
\hline Internal Forces (project) & External Forces (organization or environment) \\
\hline Strengths & Opportunities \\
\hline $\begin{array}{l}\text { Nursing leadership support } \\
\text { Financial support } \\
\text { - } \\
\text { Fall champions and ambassadors } \\
\text { Fall prevention strategies currently in place } \\
\text { Policy and procedure for fall prevention in place }\end{array}$ & $\begin{array}{l}\text { - Utilization of evidence-based educational strategies related to leadership training } \\
\text { to promote staff engagement. } \\
\text { - Proper staff training and education on accurate fall risk assessment and strategies } \\
\text { for patient/family engagement. } \\
\text { - Multidisciplinary engagement towards fall prevention. }\end{array}$ \\
\hline Weaknesses & Threats \\
\hline $\begin{array}{l}\text { - } \text { Compliance with fall prevention initiative not perceived as priority by staff } \\
\text { - Perceived lack of time by staff due to workload } \\
\text { - } \quad \text { Lack of quality training and education } \\
\text { - } \quad \text { Absence of patient and family engagement } \\
\text { - } \quad \text { Lack of quality and inconsistencies with patient teaching on fall prevention } \\
\text { - } \quad \text { Lack of internal motivation among staff to do the right thing } \\
\text { - } \quad \text { Inconsistencies and lack in frontline leadership skills in engaging staff } \\
\text { - } \quad \text { Inconsistent and inaccurate fall risk assessment }\end{array}$ & $\begin{array}{l}\text { - Legal implications related patient falls } \\
\text { - Negative impact of fall-related incidents and injuries to the institution's financial } \\
\text { outcome. } \\
\text { - Loss of trust from community } \\
\text { Institution's reputation at stake }\end{array}$ \\
\hline
\end{tabular}




\section{Appendix G}

Table 10

\section{Project Schedule}

\begin{tabular}{|c|c|c|}
\hline Steps & Time Frame & Who is Responsible \\
\hline $\begin{array}{l}\text { 1. Proposal Approval from } \\
\text { the University \& Facility }\end{array}$ & $01 / 01 / 2020-01 / 31 / 2020$ & DNP student \\
\hline 2. Meet Key stakeholders & $2 / 10 / 2020-2 / 14 / 2020$ & $\begin{array}{l}\text { CNO, Unit Director, DNP student, Fall Champions, Dept Reps (Education, } \\
\text { Risk, Quality, Resp, PT, Case Mgt, Social Work) }\end{array}$ \\
\hline $\begin{array}{l}\text { 3. Meet with Unit Fall } \\
\text { Champions \& } \\
\text { Ambassadors }\end{array}$ & $2 / 17 / 2020-2 / 21 / 2020$ & Unit Director \& DNP student \\
\hline $\begin{array}{l}\text { 4. Leader/Staff Training and } \\
\text { Education }\end{array}$ & $2 / 24 / 2020-03 / 20 / 2020$ & Education Director \& DNP student \\
\hline 5. Project Go-Live & $03 / 23 / 2020-05 / 15 / 2020$ & Fall Champions, Ambassadors, Staff, \& DNP student \\
\hline 6. Data Analysis & $05 / 18 / 2020-06 / 12 / 2020$ & DNP student \\
\hline 7. Peer Review of Study & $06 / 15 / 2020-06 / 26 / 2020$ & University and Facility \\
\hline 8. Finalize Project & $06 / 29 / 2020-07 / 24 / 2020$ & DNP student \\
\hline 9. Dissemination of Results & $07 / 27 / 2020-07 / 31 / 2020$ & $\begin{array}{l}\text { DNP student, Fall Champions \& Ambassadors, Facility Media Dept, Facility } \\
\text { leaders }\end{array}$ \\
\hline
\end{tabular}




\section{Appendix $\mathrm{H}$}

Table 11

Budget

\begin{tabular}{|l|l|l|l|}
\hline EXPENSES & & REVENUE & \\
\hline Direct & & Billing & NA \\
\hline Salary and benefits & $\$ 8,400.00$ & Grants & NA \\
\hline Supplies & $\$ 500.00$ & $\begin{array}{l}\text { Institutional budget support } \\
\text { (Salary, supplies, services, } \\
\text { celebrating success) }\end{array}$ & $\$ 12,100.00$ \\
\hline Services & $\$ 200.00$ & & \\
\hline Statistician & $\$ 400.00$ & & \\
\hline Celebrating success & $\$ 3,000.00$ & & \\
\hline & & & \\
\hline Indirect & & & \\
\hline Overhead (electricity, etc) & & & $\$ 12,100.00$ \\
\hline \multicolumn{2}{|l}{} & Total Revenue & \\
\hline Total Expenses & $\$ 12,500.00$ & \\
\hline Net Balance & & & \\
\hline
\end{tabular}




\section{Appendix I}

Table 12

\section{Data Analysis Table}

\begin{tabular}{|l|l|l|}
\hline Variables & Type of Data & Statistical Analysis \\
\hline 1. Patient's Age (in years) & Continuous & $\begin{array}{l}\text { Frequency, Percentage, } \\
\text { Mean, Median, SD }\end{array}$ \\
\hline 2. Patient's Gender & Nominal & Frequency and Percentage \\
\hline 3. Hospital Unit & Nominal & Frequency and Percentage \\
\hline 4. Shift & Nominal & Frequency and Percentage \\
\hline 5. Patient's Fall Risk Level & Nominal & Frequency and Percentage \\
\hline $\begin{array}{l}\text { 6. Staff Completion of } \\
\text { training \& education }\end{array}$ & Nominal & $\begin{array}{l}\text { Frequency, Percentage, Chi } \\
\text { Square Test }\end{array}$ \\
\hline $\begin{array}{l}\text { 7. Staff Adherence to Fall } \\
\text { TIPS protocol }\end{array}$ & Nominal & $\begin{array}{l}\text { Frequency, Percentage, Chi } \\
\text { Square Test }\end{array}$ \\
\hline $\begin{array}{l}\text { 8evel \& Risk } \\
\text { (Knowledge of fall risk } \\
\text { level \& risk factor) }\end{array}$ & Nominal & $\begin{array}{l}\text { Frequency, Percentage, Chi } \\
\text { Square Test }\end{array}$ \\
\hline $\begin{array}{l}\text { 9. Pt/Fam Engagement - } \\
\text { Intervention (Knowledge } \\
\text { of personalized fall } \\
\text { prevention intervention) }\end{array}$ & Nominal & $\begin{array}{l}\text { Frequency, Percentage, Chi } \\
\text { Square }\end{array}$ \\
\hline 10. Incidence of Fall & Continuous & Poisson Exact Model \\
\hline
\end{tabular}


Appendix $\mathbf{J}$

Table 13

Protocol Adherence and Patient Engagement Audit Form

\begin{tabular}{|c|c|c|c|c|c|c|c|c|}
\hline Patient & $\begin{array}{l}\text { Is the FALL } \\
\text { TIPS poster } \\
\text { hanging in } \\
\text { the patient's } \\
\text { room? }\end{array}$ & $\begin{array}{l}\text { Can the } \\
\text { patient or } \\
\text { family } \\
\text { member } \\
\text { verbalize the } \\
\text { patient's fall } \\
\text { risk factors? }\end{array}$ & $\begin{array}{l}\text { Can the patient or } \\
\text { family member } \\
\text { verbalize the } \\
\text { patient's } \\
\text { personalized fall } \\
\text { prevention plan? }\end{array}$ & $\begin{array}{l}\text { Patient's } \\
\text { Age }\end{array}$ & $\begin{array}{l}\text { Patient's } \\
\text { Gender }\end{array}$ & $\begin{array}{l}\text { Hospital } \\
\text { Unit }\end{array}$ & Shift & $\begin{array}{l}\text { Patient's } \\
\text { fall risk } \\
\text { level }\end{array}$ \\
\hline 1. & $\begin{array}{l}\text { Yes } \\
\text { No }\end{array}$ & $\begin{array}{l}\text { Yes } \\
\text { No } \\
\text { NA }\end{array}$ & $\begin{array}{l}\text { Yes } \\
\text { No } \\
\text { NA }\end{array}$ & & $\begin{array}{l}\text { Male } \\
\text { Female }\end{array}$ & & $\begin{array}{l}\text { Day shift } \\
\text { Night shift }\end{array}$ & $\begin{array}{l}\text { High } \\
\text { Low }\end{array}$ \\
\hline 2. & $\begin{array}{l}\text { Yes } \\
\text { No }\end{array}$ & $\begin{array}{l}\text { Yes } \\
\text { No } \\
\text { NA }\end{array}$ & $\begin{array}{l}\text { Yes } \\
\text { No } \\
\text { NA }\end{array}$ & & $\begin{array}{l}\text { Male } \\
\text { Female }\end{array}$ & & $\begin{array}{l}\text { Day shift } \\
\text { Night shift }\end{array}$ & $\begin{array}{l}\text { High } \\
\text { Low }\end{array}$ \\
\hline 3. & $\begin{array}{l}\text { Yes } \\
\text { No }\end{array}$ & $\begin{array}{l}\text { Yes } \\
\text { No } \\
\text { NA }\end{array}$ & $\begin{array}{l}\text { Yes } \\
\text { No } \\
\text { NA }\end{array}$ & & $\begin{array}{l}\text { Male } \\
\text { Female }\end{array}$ & $\begin{array}{l}\text { Yes } \\
\text { No }\end{array}$ & $\begin{array}{l}\text { Day shift } \\
\text { Night shift }\end{array}$ & $\begin{array}{l}\text { High } \\
\text { Low }\end{array}$ \\
\hline 4. & $\begin{array}{l}\text { Yes } \\
\text { No }\end{array}$ & $\begin{array}{l}\text { Yes } \\
\text { No } \\
\text { NA }\end{array}$ & $\begin{array}{l}\text { Yes } \\
\text { No } \\
\text { NA }\end{array}$ & & $\begin{array}{l}\text { Male } \\
\text { Female }\end{array}$ & $\begin{array}{l}\text { Yes } \\
\text { No }\end{array}$ & $\begin{array}{l}\text { Day shift } \\
\text { Night shift }\end{array}$ & $\begin{array}{l}\text { High } \\
\text { Low }\end{array}$ \\
\hline
\end{tabular}


Appendix K

\begin{tabular}{|l|l|l|l|l|l|l|}
\hline Increased Risk \\
of Harm If You Fall
\end{tabular}

Figure 7. Fall TIPS bedside poster (English version). (Duckworth et al., 2019) 
Appendix L

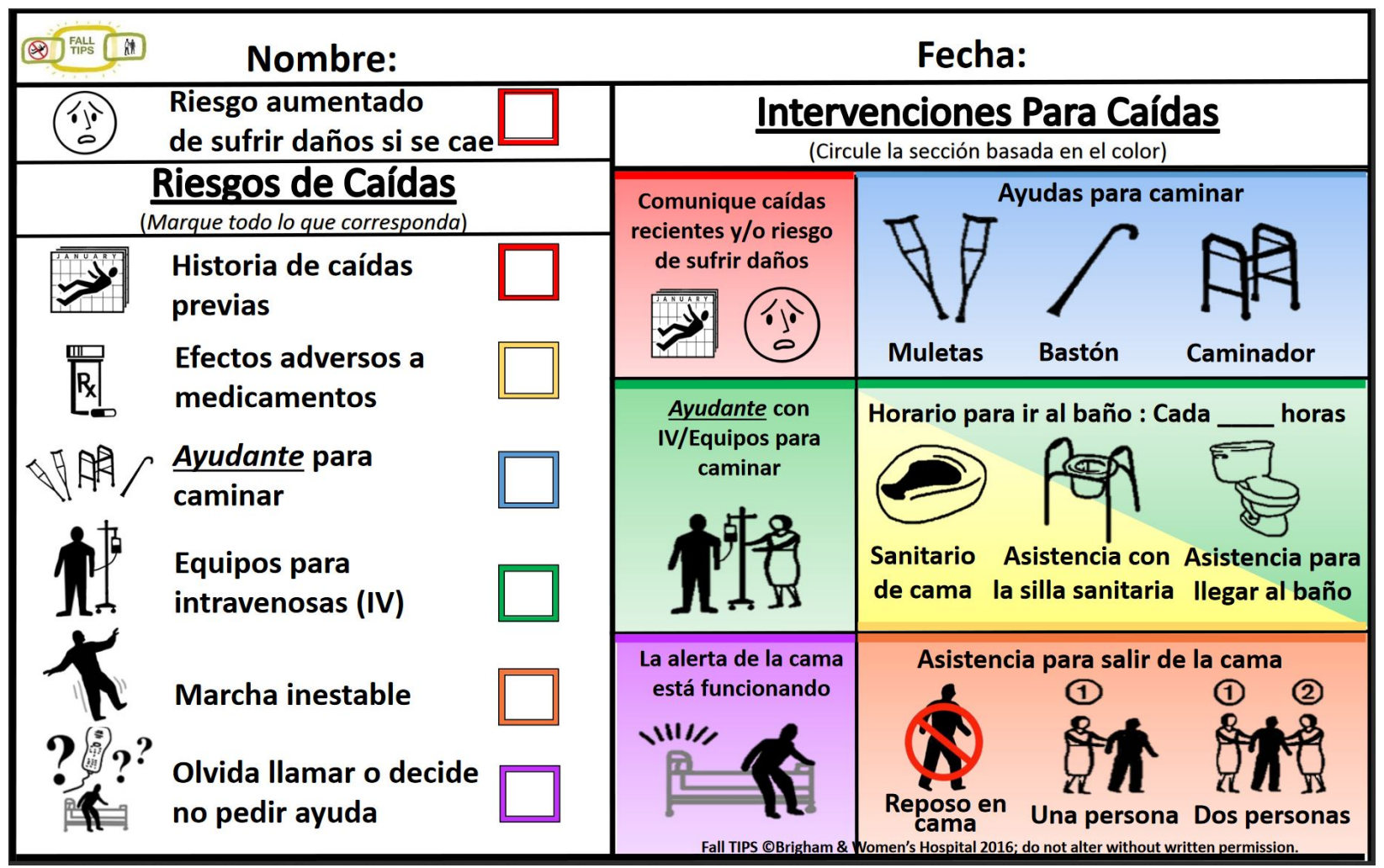

Figure 8. Fall TIPS bedside poster (Spanish version). (Duckworth et al., 2019) 
Appendix M

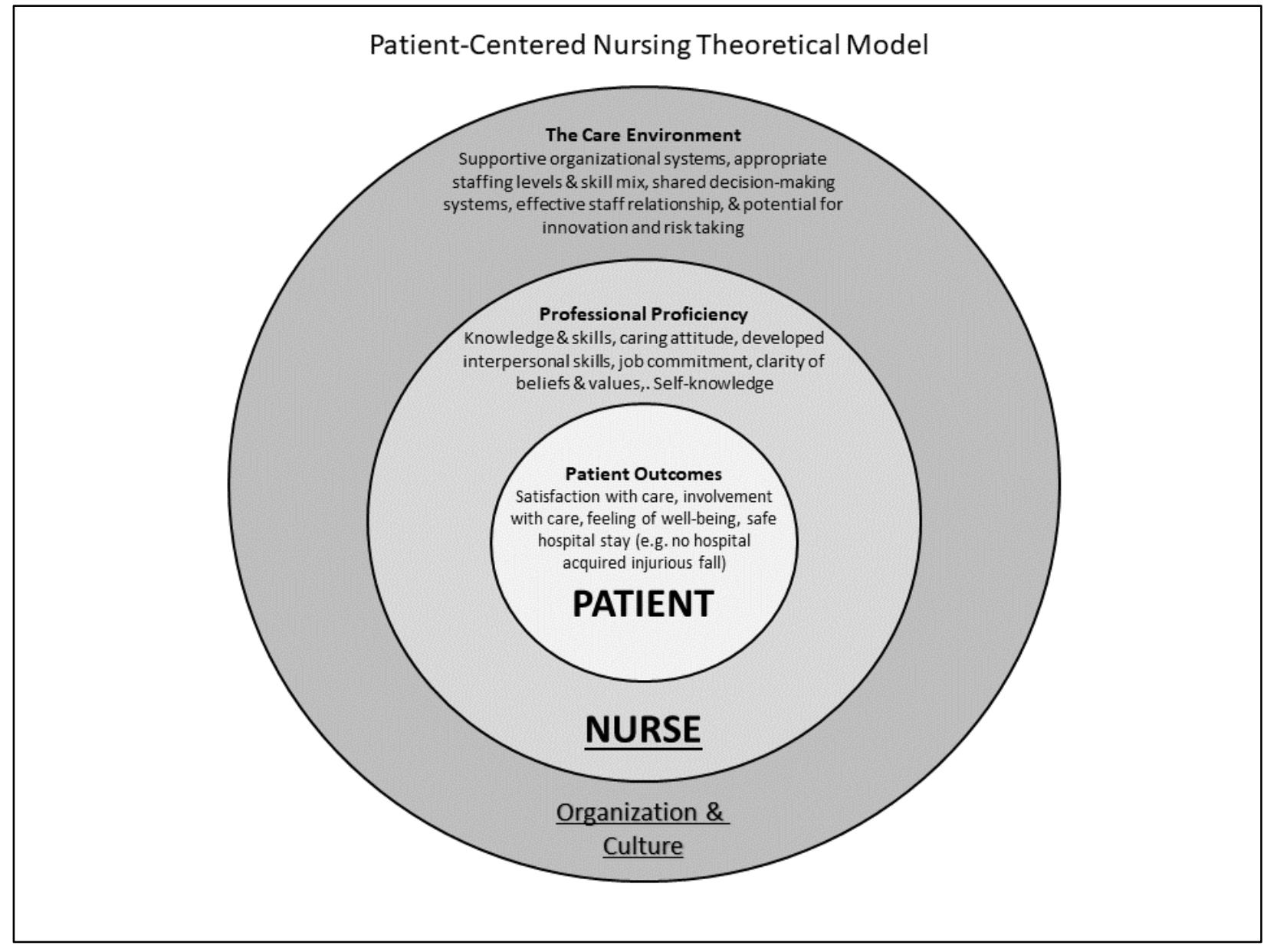

Figure 9. The person-centered nursing framework. (McCormack \& McCance, 2006) 


\section{Appendix N}

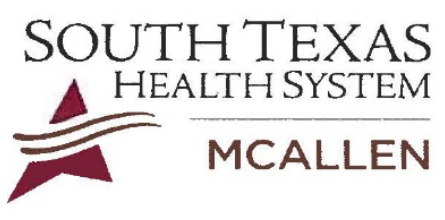

February 17, 2020

Re: Approval for Implementation of a Quality Improvement Project title, "A PatientCentered Approach to Fall Prevention."

Dear IRB Committee Members,

South Texas Health System McAllen and its Nursing Division is pleased to work with Mr. Elmer Esguerra, a DNP student, and extend full support for his quality improvement project aimed at reducing the incidence of falls among adult inpatients in our medicalsurgical units utilizing a patient-centered approach. We are aware that the components of the quality improvement project will include staff education on accurate fall risk assessment; individualized and comprehensive patient education on fall prevention; and incorporating patient engagement activities into our current fall prevention program.

Please do not hesitate to reach out with any question.

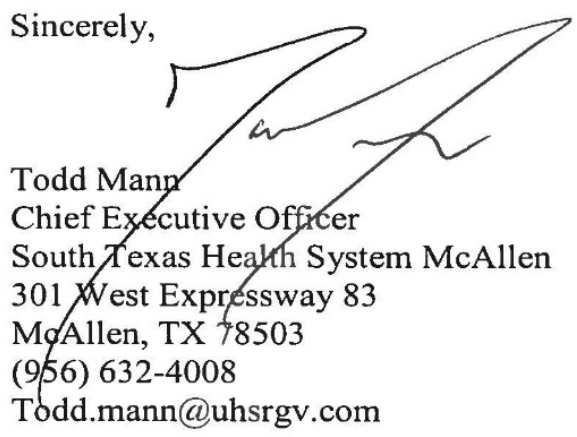

301 West Expressway 83, McAllen, Texas 78503 * 956-632-4003* www.southtexashealthsystem.com 


\section{Appendix $\mathrm{O}$}

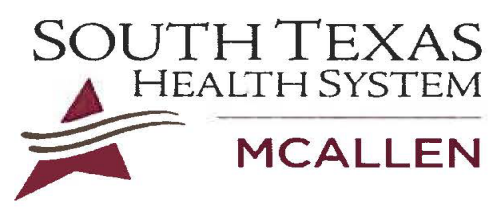

February 17,2020

Re: Approval for Implementation of a Quality Improvement Project title, “A PatientCentered Approach to Fall Prevention."

Dear Dr. Camille Payne,

South Texas Health System McAllen and its Nursing Division recognize the need to implement a quality improvement project utilizing a patient-centered approach in reducing the incidence of falls among adult patients in medical-surgical units at McAllen Medical Center.

The organization does not have an internal Institutional Review Board. However, upon the review conducted by the organization's Performance Improvement Committee of the proposed quality improvement project, we are pleased to extend our full support to $\mathrm{Mr}$. Elmer Esguerra's project proposal and approve of its full implementation in our facility.

Please do not hesitate to reach out with any question.

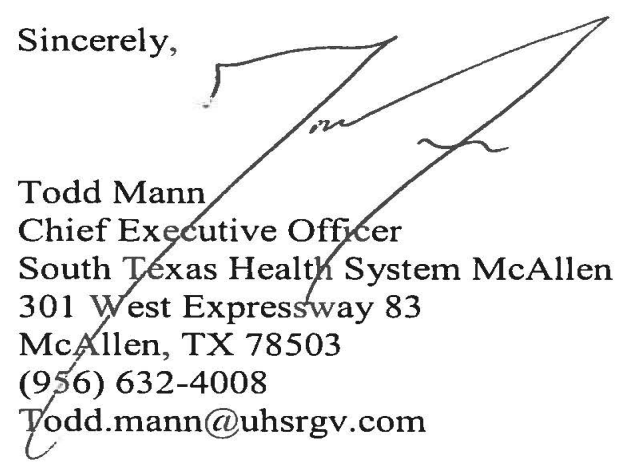

301 West Expressway 83, McAllen, Texas 78503 * 956-632-4003 * www.southtexashealthsystem.com

\section{DEFINING Healthcare}

